NBER WORKING PAPER SERIES

\title{
RETAIL FINANCIAL INNOVATION AND STOCK MARKET DYNAMICS: THE CASE OF TARGET DATE FUNDS
}

\author{
Jonathan A. Parker \\ Antoinette Schoar \\ Yang Sun \\ Working Paper 28028 \\ http://www.nber.org/papers/w28028 \\ NATIONAL BUREAU OF ECONOMIC RESEARCH \\ 1050 Massachusetts Avenue \\ Cambridge, MA 02138 \\ October 2020, Revised August 2022
}

For helpful comments, we thank Daniel Bergstresser, Stephen Cecchetti, Joel Dickson, Winston Dou, Qingyi Drechsler, Richard Evans, Xavier Gabaix, Joshua Goodman, Pierre Gourinchas, Kevin Khang, Ralph Koijen, Blake LeBaron, David Musto, Debarshi Nandy, Darby Neilson, Jim Poterba, Josh Rauh, Jonathan Reuter, Yao Zeng, and especially John Campbell, Dong Lou, Clemens Sialm, Jules van Binsbergen, and Dimitri Vayanos, as well as participants in seminars at Brandeis, Fidelity Investments, MIT, Northwestern, the Q-group, Shanghai Jiaotong, Vanguard, University ofWashington St. Louis, and the Fall 2020 NBER Asset Pricing meeting, the 2021 ASSA Meetings, the 2021 ASU SonoranWinter Conference, the 2021 SFS Cavalcade, and the 2021 FIRS Conference. The views expressed herein are those of the authors and do not necessarily reflect the views of the National Bureau of Economic Research.

NBER working papers are circulated for discussion and comment purposes. They have not been peer-reviewed or been subject to the review by the NBER Board of Directors that accompanies official NBER publications.

(C) 2020 by Jonathan A. Parker, Antoinette Schoar, and Yang Sun. All rights reserved. Short sections of text, not to exceed two paragraphs, may be quoted without explicit permission provided that full credit, including $(\odot$ notice, is given to the source. 
Retail Financial Innovation and Stock Market Dynamics: The Case of Target Date Funds Jonathan A. Parker, Antoinette Schoar, and Yang Sun

NBER Working Paper No. 28028

October 2020, Revised August 2022

JEL No. G12,G23,G51

\begin{abstract}
$\underline{\text { ABSTRACT }}$
Target Date Funds (TDFs) are designed to provide unsophisticated or inattentive investors with age-appropriate exposures to different asset classes like stocks and bonds. The rise of TDFs has moved a significant share of retirement investors into macro-contrarian strategies that sell stocks after relatively good stock market performance. This rebalancing drives contrarian flows across equity mutual funds held by TDFs, stabilizing their funding, and reduces stock returns for stocks disproportionately held by these funds when stock market returns are relatively high. Continued growth in TDFs and similar investment products may dampen stock market volatility and increase the transmission of shocks across asset classes.

Jonathan A. Parker

MIT Sloan School of Management

100 Main Street, E62-642

Cambridge, MA 02142-1347

and NBER

JAParker@MIT.edu

Antoinette Schoar

MIT Sloan School of Management

100 Main Street, E62-638

Cambridge, MA 02142

and NBER

aschoar@mit.edu

Yang Sun

Brandeis International Business School

415 South Street MS032

Waltham, MA 02453

yangs@brandeis.edu
\end{abstract}

A data appendix is available at http://www.nber.org/data-appendix/w28028 
Over the past two decades, one of the most important financial innovations for the typical American retail investor has been the development and spread of Target Date Funds (TDFs, also called life-cycle funds). A TDF is a fund of funds that invests in a number of mutual funds so as to maintain given fractions of its assets in different asset classes, such as stocks and bonds. The specific asset allocation depends on the time until the investor's expected retirement date, which is the fund's target date. As time passes and its investors age, the TDF shifts the portfolio allocation automatically from a higher equity share to a lower stock-market exposure, following the prescriptions of life-cycle models of optimal portfolio choice. $^{1}$

The rise in TDFs has been dramatic. The capital invested in TDFs and other balanced funds rose from under $\$ 8$ billion in 2000 to almost $\$ 6$ trillion in 2021, about $22 \%$ of the $\$ 27$ trillion held in US mutual funds. ${ }^{2}$ This rapid growth was facilitated by the Pension Protection Act (PPA) of 2006, which qualifies both TDFs and Balanced Funds (BF) as default options in defined-contribution retirement saving plans. Similar strategies that automatically stabilize the share of an investor's portfolio in different asset classes have recently been incorporated into a broader set of investment products, such as some automated advisory programs (e.g. model portfolios).

In this paper, we analyze the market-wide impact of TDFs on retail investor behavior. We focus on the fact that TDF strategies are macro-contrarian: after high stock market returns, TDFs' strategies require that they sell stocks to return to their prescribed asset allocations within a short period of time. Historically, a majority of retirement and retail investors are either passive - letting their portfolio shares rise and fall with the returns on different asset classes - or they are active and tend to reallocate their assets into asset classes or funds with better past performance, a behavior known as positive feedback trading or momentum trading that can amplify price fluctuations. ${ }^{3}$ In contrast, by rebal-

\footnotetext{
${ }^{1}$ Merton (1969), Viceira (2001), Cocco, Gomes, and Maenhout (2005), Duarte et al. (2021) study the characteristics of the optimal mix of stocks and bonds as people age. Campbell (2016) Section 5.1 discusses some of the benefits and pitfalls of TDFs as a solution to the life cycle portfolio problem.

${ }^{2}$ Of this, \$3.2 trillion was in TDFs including \$1.4 trillion in target date collective investment trusts (CITs) which invest like TDFs but have lower fees than the equivalent mutual funds and are primarily used by large employers. Dollar amounts are from Investment Company Institute (2022), figures 2.2, and Morningstar (2022).

${ }^{3}$ Agnew, Balduzzi, and Sunden (2003) and Ameriks and Zeldes (2004) show widespread passivity of retail investors in retirement accounts and De Long et al. (1990), Hong and Stein (1999), Lou (2012), and Vayanos and Woolley (2013) discuss the effects of momentum trading on stock returns. In contrast, Calvet, Campbell, and Sodini (2009) shows that retail investors in Sweden rebalance against idiosyncratic returns to offset about
} 
ancing to maintain age-appropriate asset allocations, TDFs trade against excess returns in each asset class, selling stocks and buying bonds when the stock market outperforms the bond market, and vice versa. The market-wide impacts of this contrarian behavior was not the primary intent of the product design of TDFs which was simply to improve the individual-level portfolio choices of inattentive or unsophisticated retail investors.

We have three main findings. First, following high stock market returns relative to bond returns, TDFs sell equity and buy fixed income mutual funds to move their portfolios back towards the desired stock-bond mix within a few months, consistent with their mandates (and the reverse following low relative equity returns). Second, as a result of this rebalancing, following high relative equity returns, equity mutual funds with larger ownership by TDFs experience lower net inflows than equity funds with smaller or nonexistent TDF ownership. Thus, TDF ownership stabilizes the fund flows to equity mutual fund. Similarly, bond funds with higher TDF ownership experience bigger net inflows following high relative equity returns. Third, we find evidence that stocks with higher TDF ownership (through the mutual funds held by TDFs) have lower returns after higher market performance consistent with the automatic rebalancing by TDFs, which leads them to sell stocks. ${ }^{4}$ In contrast to equities, rebalancing by TDFs does not appear to affect the prices of underlying bonds, potentially because funds engage in liquidity management that reduces the price impact.

Our first result confirms that TDFs rebalance across asset classes according to the desired asset allocation prescribed by their glide paths. An average TDF initially allocates 80 to 90 percent of its assets to diversified equity funds and the remainder to bond funds until 25 years before the target retirement date, at which point the equity share typically starts to decline smoothly over time to reach 30 to 40 percent 10 years after the target date. These shares are independent of market performance, so that differences in desired shares imply differences in trading behavior across TDFs in response to differential asset class returns. The amount of rebalancing by a TDF is a quadratic function of the desired equity share with a maximum at $50 \%$. When the stock market returns $20 \%$ more than the bond market, a fund with a $50 \%$ desired equity share needs to convert $4.5 \%$ of its portfolio from stocks to half of the passive changes in asset shares.

${ }^{4}$ Supporting this interpretation, we find this pattern of returns when we focus on variation in TDF ownership that is quasi-exogenously prompted by inclusion in the S\&P 500 index, and do not find this pattern in the period before the rise of TDFs. 
bonds. In contrast, a TDF invested entirely in one asset class would not have to rebalance at all.

Using quarterly data on TDF holdings during 2008-2018 and monthly returns, we find that TDFs rebalance across equity and fixed income mutual funds within a few months largely as predicted by their desired equity shares given realized asset returns. Following monthly differential returns between asset classes, we estimate that roughly $45 \%$ of the predicted rebalancing is implemented in the same month, $25 \%$ in the following month, and another $10 \%$ with a two-month lag. ${ }^{5}$ Passive TDFs (TDFs with more than $50 \%$ of assets invested in index funds) follow predictions quite closely and rebalance more rapidly. Consistent with the quadratic relationship between desired equity share and required rebalancing, we observe a greater magnitude of rebalancing in the group of TDFs with more equal allocations between equity and bonds. These are also the TDFs that have the most assets under management, since this asset allocation applies to older people.

Second, we show that the contrarian trading of TDFs in response to excess stock returns has become a quantitatively significant part of equity and bond fund flows. Importantly, this result shows that pro-cyclical flows to and out of TDFs does not off-set the contrarian rebalancing within the TDFs. For an excess return on the stock market of $10 \%$ in a month, the average equity mutual fund receives additional investment flows that increase its size by $0.4-0.8 \%$ in that month. Using differences across funds in the degree of TDF ownership, these flows are reduced by more than $20 \%$ for mutual funds with a $10 \%$ TDF ownership, which is the mean percent held by TDFs among the sample of funds with non-zero TDF ownership at any time during the period. We estimate that TDF rebalancing in aggregate offsets about $20 \%$ of aggregate "trend-chasing" flows by retail and institutional investors in mutual funds. In sum, at both the individual-fund level and at the aggregate level, the investor flows into equity mutual funds in response to excess stock returns are mitigated by TDF contrarian trading.

We also find that bond fund flows respond as we predict, but more slowly, likely due to the use of derivatives or cash holdings to mitigate price impact. When the aggregate stock market outperforms the bond market by $10 \%$, the average corporate bond fund experiences higher inflows in the same month, so that TDFs contribute to bond fund flows mainly with

\footnotetext{
${ }^{5}$ Rebalancing over months is consistent with practitioners' statements that active TDFs do not employ fixed trading schedules, do not tightly adhere to target allocations, and rebalance across asset classes to minimize price impact.
} 
a one month delay.

Third, we show that following positive excess returns on the stock market, contrarian trading by TDFs decreases returns on the stocks that TDFs hold disproportionately more of. Given the share of each fund held by TDFs and the stocks held by each fund, we calculate the (indirect) stock level holdings by TDFs. Stocks with higher indirect TDF investment tend to be larger with higher market beta, more liquid, and of higher-growth companies. Looking across all stocks while controlling for characteristics, greater TDF ownership is associated with lower individual stock returns in the same month as high stock market returns and in the following month. Specifically, when the excess return of the equity asset class is $1 \%$ in a month, stocks with a one standard deviation $(0.7 \%)$ higher share of TDF ownership have a 2.8 basis point lower four-factor adjusted return in the same month. The timing of the price effect is consistent with the speed at which different types of TDFs rebalance; some large passive TDFs (which hold index funds in their portfolios) tend to rebalance within a day, while active TDFs (which hold actively managed funds) can rebalance over a month or two.

Four pieces of evidence suggest that this price impact is not driven by other characteristics of stocks that are correlated with TDF ownership share. First, by controlling for lagged returns, we show that the well-known short-term reversal in stock returns does not explain our results. Second, we control for the effects of a full set of stock characteristics (including size, trading volume, market-to-book, dividend yield, profitability, investment, liquidity, and general mutual fund ownership that is not through TDFs) on the sensitivity of stock returns to asset class movements. Third, we find that there is no correlation between our measure of TDF ownership share and individual stock returns following aggregate market returns during 1987-2005, prior to the PPA and so prior to the rise of TDFs. Fourth, we also show that stocks that are included in the S\&P 500 index have both discretely higher TDF ownership especially by active TDFs (statistically significant) and lower returns in the month following excess stock market returns (statistically significant and the timing consistent with the speed of active TDF rebalancing) than stocks not included in the index that are otherwise similar (matched on industry, size and liquidity). However, these effects are statistically weak under a two-stage least squares specification.

Given the size of TDFs and balanced funds, the price impact of their contrarian trading implies a demand elasticity of -0.3 after we scale TDF investment to account for all target- 
date collective investment trusts (privately negotiated versions of TDFs in retirement plans) and balanced funds, meaning that purchasing $1 \%$ of the market capitalization of a stock would raise its price by $3 \%$. This price response appears large, but there are other funds and strategies that at least partly trading alongside TDFs, which would imply a smaller price response per unit change in holding. As we discuss in Section 5.2, these funds include model portfolios, hedge funds that follow a "risk-parity" strategy, and some pension funds and endowments.

Why don't other market participants arbitrage away the price impact of these contrarian trading strategies? One possibility is limits to arbitrage. Trading ahead of TDFs and similar funds may be risky due to uncertainty in the timing and magnitude of the TDF contrarian trades as well as due to the size of those funds (which may make their trades represent a risk factor, as in Dou, Kogan, and Wu, 2020). Further consistent with a high risk of arbitrage against TDF rebalancing trades, we find that the price effect of TDFs lasts for about three months.

However, a potentially more important reason is that contrarian trading by TDFs appears to be profitable during this time period, so that arbitrage capital may have joined rather than traded against TDFs. This profitability is consistent with the fact that the macro-contrarian strategies of TDFs trade against trend-chasing retail investors. To provide some evidence on this argument, we calculate the risk-adjusted returns from a long-short strategy that buys low-TDF stocks and shorts high-TDF stocks when equity outperformed bonds in the previous month. This strategy trades in the same direction as predictable trades by (mostly active) TDFs. This strategy earned a risk-adjusted cumulative return of 20 to $40 \%$ during 2010-2018 (or about 20-40 basis points per month), which suggests that it was not profitable (in a risk-factor-adjusted return sense) to trade against TDFs.

We do not find similar effects of TDF contrarian trading on bond prices, despite the fact that we do find that TDF rebalancing has significant effects on bond mutual fund flows in the expected direction. Section 7 discusses two main reasons for this difference: the use of derivatives and liquidity management.

Our findings have several implications. First, the contrarian rebalancing of TDFs dampens the price responsiveness of the stock market. A back-of-the-envelope calculation suggests that, for TDFs and balanced funds today, this effect is currently too small to be statistically detected for aggregate market movements. However, if financial products that 
embed these strategies continue to grow, the size of this effect may grow. In that case, these strategies will both increase market efficiency by smoothing out sentiment-driven fluctuations and worsen market efficiency by dampening price responses to dividend news and investor effective risk aversion.

Second, because TDFs actively re-balance between stocks and bonds, they add to co-movement in returns between these markets. An implication of this is that TDFs propagate movements in interests rates from bond markets to stock markets, for example expansionary monetary policies such as quantitative easing. Again, this effect is likely very small at the moment but would increase if retail investors continue to move money into these types of investment strategies.

Finally, our results suggest that to the extent that market momentum or other anomalies are (or were) due to trend-chasing by retail investors, these anomalies may disappear (or may have already disappeared) as more retail investor money follows market-contrarian strategies. Of course all of these effects may be mitigated by the responses of other investors or by TDFs themselves as their investment strategies evolve and/or respond to changing return dynamics.

Related Literature Our paper contributes to the literature documenting that aggregate mutual fund flows can impact equity prices at the asset-class level (Warther, 1995; Edelen and Warner, 2001; Ben-Rephael, Kandel, and Wohl, 2011; Da et al., 2018). ${ }^{6}$ In contrast, the literature on bond funds finds limited price impact of fire sales due to the liquidity buffer of mutual funds (Choi et al., 2020; Ma, Xiao, and Zeng, forthcoming). The type of fund flows examined in our paper is distinct from the literature in several dimensions. Most importantly, while the existing literature studies net fund flows that combine decisions by all investors, we focus on flows caused by largely mechanical rebalancing rules. In that sense our paper is closely related to Da et al. (2018), Evans and Sun (2021), and Ben-David et al. (forthcoming) which study flows that follow from changes in ratings. The rebalancing flows we study are also unique in that they are contrarian, and work against the effect of typical mutual fund flows (i.e., momentum) which has been the focus of much of the previous literature.

Our paper is also broadly related to the literature showing that aggregate demand

\footnotetext{
${ }^{6}$ See Peng and Wang (2021); Ben-David et al. (2021) and Coval and Stafford (2007); Lou (2012); Dou, Kogan, and $\mathrm{Wu}(2020)$ for evidence that fund flows affect factor-level and stock-level prices.
} 
is inelastic, and therefore shifts in institutional demand can generate large price impact (Koijen and Yogo, 2019; Gabaix and Koijen, 2020). Most closely related to our paper, Haddad, Huebner, and Loualiche (2021) argues that the rise of passive investing, working in the opposite direction as the rise of TDFs, lowers the elasticity of aggregate demand.

There is a substantial amount of evidence that the rise of TDFs followed from financial innovation and regulatory changes and altered investor portfolio behavior. In particular, Mitchell and Utkus (2021), using data from one large 401(k) provider, shows that plan-level features, such as auto-enrollment, are key drivers of TDF adoption, and make a sizable impact on the portfolios of the adopters (see also Chalmers and Reuter, 2020; Parker et al., 2022). And there is substantial work on differences across TDFs and its causes and impact on investors (Balduzzi and Reuter, 2019; Shoven and Walton, 2020; Brown and Davies, 2020; Massa, Moussawi, and Simonov, 2020).

\section{Background of target date funds}

This section describes TDFs, target date collective investment trusts (CITs), and balanced funds (BFs), which most TDFs transition into shortly after they reach their target dates. We discuss other mixed-asset-class funds which have pre-determined asset allocations to equity and bonds and engage in similar rebalancing activities in Section 5.2. Our main analysis focuses on the rebalancing behavior of TDFs because their holdings can be measured well and because their rapid rise affects the investment behavior of trillions of dollars of assets held by retail investors (as discussed in the introduction).

Target date funds TDFs are funds-of-funds that invest in equity and fixed income mutual funds. TDFs seek to maintain given exposures to different asset classes, with the shares based on the time to "target date." Most TDFs typically start with a large desired share of equity - on the order of 90 percent - until roughly 25 years before retirement, at which point the desired equity share declines smoothly over time to reach roughly 40 percent ten years after the target date. The sharp rise of TDFs followed the passage of the Pension Protection Act in August of 2006. The PPA qualifies TDFs to be used as default options in 401(k) retirement saving plans. As shown by the dark blue area in Figure 1, total assets invested in TDFs increased from less than $\$ 8$ billion in 2000, to $\$ 109$ billion at the end of 2006, and then rapidly increased to $\$ 1.8$ trillion at the end of 2021. TDFs with retirement 
years in 2020-2040 account for the majority of this increase (see Appendix Figure A.1). In $2021, \$ 1.2$ trillion out of the $\$ 1.8$ trillion TDF assets are held in 401(k) plans (67\%) and $\$ 336$ billion are held through IRAs (19\%) (ICI Factbook, 2022, Figure 8.20).

TDFs can be classified into "active" or "passive," based on the characteristics of the underlying mutual funds. Figure 2 plots the distribution of fractions of index funds in TDF portfolios. About $21 \%$ of the TDFs are purely index, $25 \%$ are purely active, and the rest of TDFs (about half of all observations) are "hybrid," meaning that they hold a mixture of index funds and actively managed funds. Following the terminology in the industry, we classify a TDF as "passive" if more than $50 \%$ of its assets are invested in index funds, and "active" if less than $50 \%$ of its assets are in index funds. According to practitioners, passive TDFs stick closer to their glide paths and rebalance faster than active TDFs do.

Collective investment trusts Some target date funds are structured as collective investment trusts (CITs). Large plan sponsors (employers) can negotiate with providers for lower fees or other customization, and CITs allow for these plan-specific fee arrangements. According to Morningstar estimates, total assets invested in CITs are approaching the same size as that invested in target date mutual funds as of 2021 and are growing rapidly.

Unlike mutual funds which are regulated by the Securities and Exchange Commission (SEC) under the Investment Company Act of 1940, CITs are not subject to SEC regulation and do not file annual reports with the SEC. As a result, data on CITs are generally difficult to obtain. However, the large target-date CITs are simply lower-fee versions of their mutual fund counterparts, and we make the assumption that holdings of CITs overlap with those of TDFs. TDFs and CITs managed 3.2 trillion dollars at the end of 2021 (Figure 1).

Balanced funds Balanced funds (BFs) hold equity and bonds with fixed weights typically $60 \%$ equity and $40 \%$ fixed income - but do not adjust the weights over time. Many TDFs turn into balanced funds-of-funds after reaching the bottom of their glide paths and behave much like their TDF "parent" funds. Some BFs are funds-of-funds investing in other mutual funds thus pursuing similar strategies as TDFs (Figure B.2 panel A), but others invest directly in stocks and bonds, or hold a combination of mutual funds and individual securities (Figure B.2 panel B). While these BFs also need to rebalance after excess asset class returns, their rebalancing involves endogenous security selection, and thus the impact across individual stocks can be different from that of TDFs. Figure 1 shows that the total assets invested in TDFs, target date CITs, and BFs together were at slightly 
less than $\$ 6$ trillion by the end of 2021 .

\section{Data}

Our analysis and data are organized along three levels: TDFs, the underlying mutual funds they hold, and the securities TDFs invest in through these underlying mutual funds.

TDFs We obtain quarterly fund characteristics and holdings of TDFs from the CRSP Mutual Fund Database. TDFs are identified from fund names containing target retirement years at five-year intervals ranging from 2000 to 2065, then manually cleaned using the TDF series names listed in the Morningstar annual TDF research reports. Most holdings of TDFs are other mutual funds which we link to the CRSP mutual fund database using the CUSIP codes of the share classes. We use this matching to categorize each holding as domestic equity, foreign equity, or fixed income. Though funds may have different fiscal quarters, calendar-quarter-end is voluntarily reported in most cases (Schwarz and Potter, 2016). We therefore keep the TDF holdings data at the level of calendar quarters to unify the timing across funds.

We restrict the TDF sample in the following ways. First, we drop observations where the value of a holding is larger than the total net assets (TNA) of the mutual fund share class, or where the sum of holdings (including mutual funds and cash) is above $110 \%$ or below $90 \%$ of the TNA of the TDF, because these are possible data errors or TDFs whose holdings cannot be well identified. Second, we drop cases where a TDF's size increases by more than $50 \%$ from the previous quarter, to exclude fund mergers, and where the equity share of a TDF shifts by more than $\pm 5 \%$ from the previous quarter, to exclude glide path adjustments (see Figure A.2 for an example of glide path adjustment). Further, we exclude small TDFs with TNA below $\$ 10$ million. These restrictions serve to avoid mis-measurement and outliers in TDFs' trading behavior which may be mis-classified as rebalancing. We follow these restrictions throughout the paper. They improve the fit of our rebalancing model, but do not affect the results on fund flows or asset returns in any significant way.

Table 1 presents the summary statistics on the TDFs in our final sample. $33 \%$ of the TDFs in our panel are classified as passive. The mean asset size is $\$ 2.6$ billion while the median is $\$ 410$ million, implying a high degree of market concentration. Each TDF on 
average holds 15 mutual funds. The average equity weight is $74 \%$, out of which $47 \%$ is in domestic equity and $27 \%$ in foreign equity, and the fixed income weight is $26 \%$, including $3 \%$ held in cash. The fund flow rate to TDFs suggests high growth during this period - the average TDF grows by $4.7 \%$ per quarter from net inflows. The allocations of new flows have an impact on TDF trading, and as will be explained in Section 3, we subtract "flow-driven" trades by TDFs from their total trades to calculate the trades that are due to rebalancing.

Equity mutual funds We construct a dataset on the underlying mutual funds from CRSP. We focus on domestic equity mutual funds with CRSP objective codes starting in ED and sold to retail and institutional investors, and combine different share classes to the fund level. For each mutual fund, we calculate the percent ownership by TDFs as the sum of TDF holdings across all share classes of the fund divided by the total fund size. TDF-invested mutual funds are rising and range between $2 \%$ and $10 \%$ of observations during the time period, however, they account to between $6 \%$ and $47 \%$ of total assets in domestic equity funds. Our sample of domestic equity funds include monthly observations on retail and institutional funds held by any TDF during our sample period 2009-2018 (see Appendix A, Table A.1 panel A for summary statistics of the equity funds). ${ }^{7}$

Individual stocks We assemble our panel dataset of monthly stock return, price, volume, and market capitalization from CRSP, and financial data from Compustat. The sample contains stocks traded on the New York Stock Exchange, NASDAQ, and American Stock Exchange. We further employ Thomson Reuters and MFLINKS to quantify the holdings of stocks by TDFs through mutual funds. Following Jegadeesh and Titman (2001), we drop stocks with market capitalizations that place them in the bottom $5 \%$ of NYSE stocks, or with beginning-of-month prices below $\$ 5$ (penny stocks), due to the lack of liquidity. We describe the risk-adjustment methods, stocks characteristics, and how we control for their effects in the analysis of stock returns in Section 5.1. Table A.1, panel B, presents the summary statistics of the stock sample.

Asset-class returns To evaluate whether TDFs' rebalancing behavior fits the model, our approximation for the equity asset class return uses either a weighted-average return

\footnotetext{
${ }^{7}$ While one might think it useful to contrast behavior across institutional and retail share classes, Boyson (2019) shows that dual-registered investment advisers have steadily converted clients' investments from retail share classes to institutional share classes since 2007. Thus, we combine retail and institutional share classes in our analysis and will refer to the sample as "retail/institutional" throughout the paper, however, our results are similar if we restrict the sample to retail share classes only.
} 
between U.S. and international equity markets or the U.S. equity market return alone. We then use the U.S.-only equity market return for flow and return analysis, because it is exogenous to discretionary portfolio selections at TDFs. The total return of the U.S. equity market comes from CRSP, the total return of the international equity market is approximated using the pre-fee return on the Vanguard Total International Stock Index Fund, and the return on bonds as an asset class is approximated using the pre-fee return on the Vanguard Total Bond Market Index Fund.

Bond funds and corporate bonds Data on corporate bond mutual funds come from CRSP, and we identify corporate bond funds as those with Lipper classifications of A, BBB, HY, SII, SID, IID, or CRSP objective codes starting in IC. Data on corporate bonds come from WRDS Bond Returns.

\section{TDF rebalancing}

This section first lays out a simple model to quantify how TDFs with different desired equity shares should rebalance in response to realized relative returns between stocks and bonds. We then describe how we measure rebalancing by each TDF. Third, we show that TDFs rebalance their stock positions by about $80 \%$ of the amount predicted by our simple model within a couple of months following different asset-class returns, and discuss why it is not $100 \%$. Finally, we estimate that TDFs on average rebalance into and out of bonds at about the same speed but only $60-70 \%$ of the predicted amount.

\subsection{Desired equity shares and TDF rebalancing}

This subsection shows that the amount of equity or bonds that a TDF must sell in response to a positive excess return on that asset class is quadratic in its desired share in that asset class with a maximum at a 50\%. We derive this result by first assuming no net inflows or outflows to the TDF and then for a general case with flow-driven trades.

Consider a TDF with $\$ 1$ of assets, a target weight of $S^{*}$ invested in equity funds and a target weight of $1-S^{*}$ invested in bond funds. Further assume that the TDF is at its target allocation at the beginning of the period and that the target shares do not change (no move along the glide path) by the period end. Assuming no investor flows, column (1) in 
panel A of Table 2 shows that the total portfolio value is $1+R^{B}+S^{*}\left(R^{E}-R^{B}\right)$ following equity and bond asset returns of $R^{E}$ and $R^{B}$ respectively. Note that $R^{E}$ and $R^{B}$ incorporate the assumption that all dividends paid out by the underlying mutual funds are reinvested by the TDF, and all dividends declared by the TDF are reinvested, consistent with TDF and retirement investor common practice. ${ }^{8}$ To restore the original asset allocation, the TDF needs to bring the equity and bond fund values to $\left[1+R^{B}+S^{*}\left(R^{E}-R^{B}\right)\right] S^{*}$ and $\left[1+R^{B}+S^{*}\left(R^{E}-R^{B}\right)\right]\left(1-S^{*}\right)$ respectively (column 2$)$. Thus, the TDF needs to sell the equity fund in the amount of $-S^{*}\left(1-S^{*}\right)\left(R^{E}-R^{B}\right)$, and buy the same amount of the bond fund (column 3). The important result is that the amount of trading is quadratic in desired equity share, with a maximum at $50 \%$.

Table 2 panel $\mathrm{B}$ considers the case of rebalancing when the TDF receives a net flow of $F$ from investors following the returns. As shown in column 4, for the purpose of allocating net flows only, the TDF needs to allocate new flows to asset classes in proportion to its desired holdings by buying $F S^{*}$ in equity (or selling if $F<0$ ) and $F\left(1-S^{*}\right)$ in fixed income. Subtracting these flow-driven trades from the total trades, we can back out the rebalancing trades, which are the same as those in panel $\mathrm{A}$, and thus also quadratic in $S^{*}$.

Two final points deserve mention. First, while some TDFs rebalance daily, others tend to trade back to their desired equity shares over a month or two or allow even longer-term deviations (some glide paths only specify a desired range). Second, a TDF can potentially reduce tradings costs by rebalancing slowly over time by purchasing the asset class that it needs more of with fund inflows (or selling the asset class it needs less of to satisfy redemptions). However, it is important to note that whether or not a TDF rebalances immediately or experiences inflows or redemptions, the cumulative net effect of TDF rebalancing trades on asset demand is still given by Table 2 panel B. In our subsequent analysis, we focus on the effect of TDF trading driven by automatic rebalancing and exclude trading driven by inflows and outflows because these latter flows are driven by factors such as market timing, auto-enrollment, auto-escalation, withdrawals, or retirement menu choices that are potentially spuriously correlated with market returns.

\footnotetext{
${ }^{8} \mathrm{TDFs}$ have the option to automatically reinvest dividends in the underlying mutual funds. We learned from practitioners that in almost every instance, TDFs choose to dividend-reinvest. Moreover, practitioners told us that $99 \%$ of investors in TDFs dividend-reinvest at the TDF level due to 401(k) plans automatically reinvesting dividends.
} 


\subsection{Calculating rebalancing trades}

We use our panel dataset of quarterly holdings at the TDF level to calculate rebalancing trades in equity and fixed income by TDF $k$ in quarter $q$ in three steps. Our calculation assumes all rebalancing trades are made at the end of each period after returns are realized and before the fund reports its portfolio. First, we calculate the dollar amount of the "total trade" for each pair of TDF $(k)$ and fund share class $(c)$ as the change in the value of holdings in excess of the value predicted by the quarterly share class return, that is, Total Trade ${ }_{c k q}=$ $M V_{c k q}-M V_{c k, q-1}\left(1+r_{c q}\right)$. The calculation includes the cases of investment initiations (where $M V_{c k, q-1}=0$ ) and terminations (where $M V_{c k q}=0$ ). Second, we aggregate the observations from each holding to the TDF-by-asset-class level and obtain TotalTrade $\mathrm{kq}^{y}$ where $y$ stands for either the equity $(E)$ or the fixed income $(B)$ asset class. Third, we calculate the "flow-driven trade" by a TDF of an asset class as the dollar flow to the TDF allocated pro rata to lagged portfolio weight of the asset class (as in Frazzini and Lamont, 2008). ${ }^{9}$ We calculate "rebalancing trade" from the difference: Rebalancing $g_{k q}^{y}=$ TotalTrade $e_{k q}^{y}-$ FlowDrivenTrade $_{k q}^{y}$. To match the setup in Table 2, where the total assets of the TDF are assumed to be one dollar, we normalize the dollar rebalancing trades by the lagged total assets of the TDF. It is important to note that our calculation assumes that all residual trades by TDFs apart from the allocations of flows are rebalancing trades. However, this measure also includes other active trading strategies pursued by TDFs as well as the move along the glide paths. ${ }^{10}$

Table 1 includes summary statistics on the quarterly total trades and rebalancing trades by TDFs during 2008-2018. While the mean and median total trades are positive during the sample period, rebalancing trades are much smaller in magnitudes. During the period, TDFs on average sell equity and buy bond funds for rebalancing purpose, which makes sense given the strong growth in the equity market. The statistics also show that subtracting flow-driven trades significantly reduce the standard deviations in the TDF trades' measures, suggesting that investor flows are noisy.

\footnotetext{
${ }^{9}$ We follow the formula commonly used in the literature to impute net fund flows: DollarFlow $w_{k q}=$ $T N A_{k q}-T N A_{k, q-1}\left(1+r_{k q}\right)$, where TNA $A_{k q}$ is the total net assets of TDF $k$ in quarter $q$ and $r_{k q}$ is the net return of the TDF.

${ }^{10}$ As explained in Section 2, fund mergers and glide path adjustments also lead to large outliers in the residual measure, and we exclude those cases from our analysis.
} 


\subsection{TDF rebalancing in response to asset-class returns}

This subsection shows that rebalancing into and out of the stock market is quite close to the amount of predicted rebalancing as derived in subsection 3.1, and is mostly completed within a couple of months. In the bond market, rebalancing is typically not as strong as we predict, spread out over a couple of months, and has significant heterogeneity across funds.

Although holding data is only available at a quarterly frequency, we infer the monthly speed of rebalancing by estimating the following equations where $k$ indexes TDFs, $q$ indexes quarter, and $m$ indexes months within each quarter:

$$
\begin{aligned}
\text { Rebalancing }_{k q}^{E}= & \Sigma_{m=1}^{3} \eta_{q m}^{E}\left[-S_{k, q-1}\left(1-S_{k, q-1}\right)\left(R^{E}-R^{B}\right)_{q m}\right] \\
& +\pi^{E}\left[-S_{k, q-1}\left(1-S_{k, q-1}\right)\left(R^{E}-R^{B}\right)_{q-1}\right]+\theta^{E} \mathbf{X}_{k q}+\delta_{k}+\epsilon_{k q}^{E} \\
\text { Rebalancing }_{k, q}^{B}= & \Sigma_{m=1}^{3} \eta_{q m}^{B}\left[S_{k, q-1}\left(1-S_{k, q-1}\right)\left(R^{E}-R^{B}\right)_{q m}\right] \\
& +\pi^{B}\left[S_{k, q-1}\left(1-S_{k, q-1}\right)\left(R^{E}-R^{B}\right)_{q-1}\right]+\theta^{B} \mathbf{X}_{k q}+\delta_{k}+\epsilon_{k q}^{B}
\end{aligned}
$$

where the dependent variable is the rebalancing trade in quarter $q$ divided by the TDF asset size in quarter $q-1$ winsorized at $1 \%$ and $99 \%$. The right hand side variables are: measures of predicted rebalancing $\left( \pm S(1-S)\left(R^{E}-R^{B}\right)\right)$ in each month $m$ of the contemporaneous quarter and in the previous quarter $q-1$; a set of time-varying TDF-level control variables $\mathbf{X}$; and TDF fixed effects $\delta$. We include the control variables and fixed effects in order to control for other trading strategies pursued by TDFs such as moving along the glide paths and/or cross-sectional stock selections. The controls are the logarithms of lagged sizes of the TDF and the TDF series, the cash share in the TDF portfolio, investor net flow to the TDF, TDF quarterly return, and years to retirement. We cluster standard errors two ways by TDF and quarter.

Under the assumption that monthly differential asset class returns are (very close to) serially uncorrelated, the key coefficients $\eta_{q m}$ measure the share of the predicted rebalancing in response to the asset price movement in month $m$ completed by the end of quarter $q$. Our conversations with practitioners suggest that TDFs often rebalance over months either to minimize trading costs and price impact or to pursue discretionary cross-asset class strategies such as momentum or market timing. Some TDFs specify only target bands for portfolio shares rather than exact numbers. If TDFs rebalanced immediately and perfectly, 
we would expect $\eta_{q 3}=\eta_{q 2}=\eta_{q 1}=1$. If TDFs rebalanced with delay, we would expect $\eta_{q 3} \leq \eta_{q 2} \leq \eta_{q 1}$, and $\Sigma_{m=1}^{3} \eta_{q m}<1$ because some rebalancing due to returns in the current quarter would be done in the subsequent quarter, an effect measured by $\pi$ (expected therefore to be positive).

Table 3, panel A presents the estimates of equation (1). Because foreign equity is a non-trivial fraction of the average TDF's portfolio (Table 1), columns 1-4 measure $R^{E}$ by the weighted-average return between domestic equity and foreign equity weighted using lagged TDF portfolio weights, thereby $R^{E}$ depends on TDF-specific exposures to the domestic- and foreign-equity (sub-)asset classes. First, we find that during a quarter, TDFs rebalance roughly $80 \%$ of the amount predicted by our simple model. Columns 1-2 of panel A show that TDFs rebalance $44 \%$ of the predicted amount of equity in the same month as the return differential (row 1). By the following month after the return differential, $70 \%$ of the predicted rebalancing is implemented, and by two months afterwards, $83 \%$ is implemented (rows 2 and 3). Assuming TDFs do not act differently at calendar quarter ends, these coefficients trace out the speed of rebalancing for the average TDF in equity funds. Including control variables (column 2) makes little difference on the estimated coefficients. $^{11}$

Our second main result is that passive TDFs rebalance more rapidly and more completely than active TDFs do. Splitting our sample of TDFs according to whether the majority of assets are invested in index funds or actively managed funds, column 3 of panel A shows that $50 \%$ of the predicted rebalancing is implemented within the same month for passive TDFs, and $85 \%$ by the end of the quarter. In contrast, column 4 shows that about $40 \%$ is implemented by active TDFs within the same month, an amount which is not statistically significant. Moreover, passive TDFs complete rebalancing within the same quarter, whereas $27 \%$ of active TDFs' rebalancing spills over into the following quarter. Overall, as expected, passive TDFs adhere more closely to their desired asset allocations than active TDFs.

Turning to the fit of the regressions, Panel A of Table 2 further shows that our explanatory variables including our measures of predicted rebalancing explain only $23 \%$ of the variation in the quarterly rebalancing trades for active TDFs and only $43 \%$ for passive

\footnotetext{
${ }^{11}$ Among the control variables, only the net flow to TDF has a significant negative coefficient, which can be attributed to the assumption that all flows to the TDF are allocated to underlying funds. Thus, we overstate flow-driven trades and understate rebalancing trades if TDFs do not allocate all flows. Before excluding glide path adjustments and fund mergers, cash also shows up as a significant (positive) determinant for rebalancing trades, but cash is no longer a significant determinant when those special cases are excluded.
} 
TDFs. ${ }^{12}$ There are three reasons for the low R-squared.

First, TDF providers vary significantly in how closely they follow their prescribed glide paths. Vanguard TDFs - passive funds that (almost surely) adhere very closely to their prescribed glide paths - have an R-squared of close to $90 \%$ (results in Table A.3). In contrast, other TDF series have much lower R-squareds around 30-40\% (even passive TDFs from other providers), though some with low R-squared have high coefficients, suggesting they stay close to the glide paths in the long term despite short-term variations in strategies.

Second, predicted rebalancing is measured with error. While $R^{E}$ and $R^{B}$ in the derivation in Section 3.1 refer to TDF-specific returns on the equity and bond portfolios of the TDF, we focus only on returns driven by asset-class level returns in our empirical analysis. The reason is that asset-class returns are exogenous to the portfolio selection problem of the TDF. In columns 1-4, we exclude the effect of idiosyncratic returns of TDFs by focusing on the (weighted-average) return of U.S. and foreign equity; in columns 5-8, we further use the return of U.S. equity only to approximate for $R^{E}$. The fit with the model is better (both coefficients and R-squared are higher) when foreign equity is considered. Despite this, we focus on U.S.-only equity market return in the rest of this paper because for many TDFs, foreign-equity exposure is time-varying and discretionary, and because there is little loss in this simplification (the correlation in monthly returns between domestic and foreign equity returns is high 0.89$).{ }^{13}$

The third reason for a low fit in these regressions is measurement error in desired equity shares, $S^{*}$. Partly, this error reflects the fact that we do not directly observed desired equity shares and use the lagged share instead. ${ }^{14}$ Further, some funds use derivatives to alter their exposure to asset-class returns, and derivatives appear as cash rather than equity or fixed income in the quarterly reports. According to asset managers, the use of derivatives is

\footnotetext{
${ }^{12}$ We exclude glide path adjustments and fund mergers which increased the R-squared by about $10 \%$ relative to our analysis in an earlier working paper version.

${ }^{13}$ While idiosyncratic returns also predict rebalancing, the implications of that for mutual fund flows and stock prices are unclear because of the endogenous selection by active TDFs. If an active TDF owns an outperforming sector or stock (indirectly), it is unclear that the active TDF will sell this winner sector/stock during rebalancing because it has an allowance to pursue cross-sectional momentum strategies. Moreover, the selections by different TDFs may be in different directions and may cancel out once the trades are aggregated to the stock level (see Bhattacharya, Lee, and Pool, 2013). As it is not central to our paper, we leave the topic of how active TDFs select and rebalance across funds to a separate paper.

${ }^{14}$ E.g., if TDFs do not fully return to their targets each period, equity share measured in $q-1$ would be biased, but we obtain almost identical results if we measure the desired equity share in $q-2$.
} 
particularly prevalent in fixed income due to the relative illiquidity of the bond market. ${ }^{15}$

Turning to fixed income, Table 3, Panel B, presents the same set of estimates as Panel A but for TDF rebalancing into and out of bonds following equation (2). Two results contrast with those for equity in panel A. First, the coefficients in the subsample of active TDFs are much smaller in panel B than in panel A, which may be due to the higher cash holdings at active TDFs (see Figure A.4) and cash counting as part of fixed income in a rebalancing model based on an equity share. Thus, active TDFs may sell equity and keep cash, instead of buying fixed income, to maintain the equity share. Second, passive TDFs appear to be slower than active TDFs when rebalancing fixed income: the coefficient on the contemporaneous month (first row) is close to zero for passive TDFs, but larger and significant for active TDFs. We find evidence that the slower rebalancing in bonds is driven by the use of derivatives (that we do not observe) to rebalance exposures to the bond market due to higher liquidity in the market for fixed income derivatives. This explanation is also confirmed by TDF managers. In line with this explanation should be passive TDFs more likely than active funds to use fixed income derivatives because they tend to be larger and need to rebalance more quickly. ${ }^{16}$

To conclude this section, Figure 3 presents a simple exercise summarizing our main results and the variation that drives them. We divide the TDF-quarterly level observations into groups based on equity share at the start of each quarter $q$ (for example, $(0.4,0.5],(0.5$, $0.6])$, calculate the ratio of rebalancing during $q$ to $\left(R^{E}-R^{B}\right)_{q}$ for all observations, and plot the median ratio (multiplied by 0.1 so as to show the amount of rebalancing for each $10 \%$ movement in $R^{E}-R^{B}$ ) of each group as a function of the equity share. The median in each bin is taken across time and across TDFs. As a reference, we also plot the quadratic functions $S^{*}\left(1-S^{*}\right)$ and $-S^{*}\left(1-S^{*}\right)$ as the predicted values for equity and bonds.

The median rebalancing in stocks and bonds in response to a $10 \%$ excess return on equity in a quarter fits the quadratic function well for equity and slightly less well for bonds

\footnotetext{
${ }^{15}$ Our rebalancing model is based on two asset classes with a specified equity share (which describes TDFs like T. Rowe Price (Figure A.3, panel B). We also estimate in Table A.4 the fit of rebalancing with a three-asset-class model, including domestic equity, foreign equity, and fixed income. Overall, both the coefficients and the R-squareds are lower in the three-asset-class model, suggesting rebalancing with respect to an equity share is a better description of the data.

${ }^{16}$ Consistent with this observation, we find that smaller passive funds that are less in need of using derivatives appear to rebalance more rapidly and more completely using bonds. Similarly, when differential asset class returns are small so again we would expect less use of derivatives, we estimate that passive TDFs rebalance in fixed income more completely and more rapidly than active funds (Appendix Tables A.5 and A.6).
} 
(Panels (a) and (b) of Figure 3). For example, when $R^{E}-R^{B}=10 \%$, a TDF with 0.65 equity share is expected to sell $2.3 \%$ of its portfolio value in stocks, which is also what the median fund sells. Rebalancing with respect to bonds also has a quadratic shape, but the magnitude is lower than predicted. In panels (c)-(f), we break down the TDF sample by passive and active TDFs. The results suggest that the smaller magnitude in bond rebalancing is driven by the active TDFs, for reasons discussed above. The wedge between predicted and actual gets bigger for active TDFs closer to retirement (smaller equity share), again consistent with the higher cash holdings in that subgroup.

\section{The effect of TDFs on net flows to mutual funds}

In this section, we show how automatic rebalancing by TDFs impacts fund flows into different mutual funds, then quantify how much TDFs reduce trend-chasing investment flows in the aggregate for equity mutual funds, in preparation for the return analysis in Section 5 .

\subsection{Fund-level evidence}

We use our monthly panel of mutual fund flows that includes both retail and institutional share classes, as described in Section 2, from July 2008 to December 2018 to match the time period of available TDF holdings data. Since we previously showed that TDFs typically rebalance within 1-2 months of realized asset class returns, we examine the sensitivity of fund flows to both the current month and the lagged month's differential asset class performance in proportion to the fraction of the mutual fund that is held by TDFs (at the end of the previous quarter). Our regression specification is:

$$
\begin{aligned}
& \text { FundFlow }_{j, m}=\beta_{1}\left(R^{E}-R^{B}\right)_{m}+\beta_{2}\left(R^{E}-R^{B}\right)_{m} \times \text { Frac.TDF }_{j, q-1} \\
& \quad+\beta_{3}\left(R^{E}-R^{B}\right)_{m-1}+\beta_{4}\left(R^{E}-R^{B}\right)_{m-1} \times \text { Frac.TDF F }_{j, q-1}+\gamma \text { Frac.TDF } F_{j, q-1} \\
& +\beta_{5}\left(R^{E}-R^{B}\right)_{m} \times \text { Index }_{j}+\beta_{6}\left(R^{E}-R^{B}\right)_{m-1} \times \text { Index }_{j}+\theta X_{j, m}+\xi_{j}+\epsilon_{j, m}
\end{aligned}
$$

where the dependent variable is the fund flow rate for mutual fund $j$ in month $m$ measured as the growth rate in assets in excess of the realized net fund return, or $\frac{T N A_{j, m}-T N A_{j, m-1}\left(1+r_{j, m}\right)}{T N A_{j, m-1}}$ where $T N A_{j, m}$ refers to the total net assets and $r_{j, m}$ refers to net return. 
The main coefficients of interest measure the contemporaneous $\left(\beta_{2}\right)$ and lagged $\left(\beta_{4}\right)$ effect of greater TDF investment on fund flows following a positive return on the asset class of the fund. In the equity fund sample, based on TDFs' trading behavior, we expect $\beta_{2}$ and $\beta_{4}$ to be negative. In contrast, we expect $\beta_{1}$ and $\beta_{3}$ to be positive for equity funds because flows are on average chasing aggregate market returns (Warther, 1995; Edelen and Warner, 2001; Ben-Rephael, Kandel, and Wohl, 2011). Similarly, we expect $\beta_{2}$ and $\beta_{4}$ to be positive in the bond fund sample, because TDFs rebalance into bonds when equity outperforms. To our knowledge, the bond fund literature has not established how bond fund flows respond to differential asset class returns. ${ }^{17}$ Equation (3) further allows the differential asset class returns to interact with an indicator for index funds to allow for potential different return-chasing dynamics in index funds and actively managed funds.

We estimate equation (3) using only mutual funds with some TDF ownership at some point during the sample to avoid a large number of zeros in the regressions (with similar results using the entire sample). Since percent flow rates are noisy, especially for smaller funds, we drop observations below $1 \%$ or above $99 \%$ within the distribution for each asset class. Control variables $X_{j, m}$ include fund characteristics that have previously been found to affect fund flows, specifically fund size, fund family size, fund age, net expense ratio, and return volatility. To allow for the correlations in errors in cross sections and within the same fund over time, we cluster standard errors two-ways by time and fund.

Table 4, column 1 presents the estimates of equation (3) in the domestic equity fund sample. First note that the coefficients on $\left(R^{E}-R^{B}\right)_{m},\left(R^{E}-R^{B}\right)_{m-1}$ and on their interactions with Index suggest that equity fund flows chase equity market performance and slightly more so in index funds. An $R^{E}-R^{B}$ of $10 \%$ leads to a higher monthly net flow at about $0.4 \%$ of the lagged size of the fund or about $0.8 \%$ higher in index funds. ${ }^{18}$

But this trend-chasing behavior is significantly reduced for funds with higher TDF ownership. The coefficients on the interaction terms with TDF ownership ( $\widehat{\beta_{2}}$ and $\widehat{\beta_{4}}$ ) suggest that if $10 \%$ of an actively managed mutual fund's assets are held by TDFs (the mean in the regression sample), the same-month return-chasing tendency is reduced by

\footnotetext{
${ }^{17}$ Goldstein, Jiang, and $\mathrm{Ng}$ (2017) and Chen and Qin (2017) both show that bond fund flows are sensitive to risk-adjusted returns, and Chen and Qin (2017) further shows that flows to bond funds follow the return of the aggregate bond market, however, these papers do not answer how bond fund flows respond to returns of the equity market.

${ }^{18}$ Table A.7 columns 1-3 confirm that this trend-chasing relationship also holds in domestic equity mutual funds which do not have any TDF investment.
} 
about $23 \%(0.093 \times 0.1 / 0.04)$ from the baseline. Fund flows are negative following a positive excess return on the stock market for funds with TDF ownership exceeding $43 \%$, which applies to about $7 \%$ of the observations in the regression sample.

The result that TDF ownership in mutual funds has a significant contrarian effect on equity fund flows implies that investor flows in and out of TDFs do not undo the automatic TDF rebalancing that we documented in the previous section. This is not a guaranteed result, because if investor flows had been highly trend-chasing, forcing TDFs to allocate the trend-chasing flows, net fund flows to TDF-held funds would not be contrarian. Moreover, $\widehat{\beta_{2}}$ and $\widehat{\beta_{4}}$ are similar in magnitude, consistent with the timing of rebalancing by TDFs that we found in the previous section. Together these results are consistent with TDFs causing contrarian flows and inertia in investor flows to TDFs.

In columns 2-3, we split the mutual fund sample by index and actively managed funds. First, the contrarian effect is stronger in index funds than in actively managed funds. Second, rebalancing in index funds is stronger in the contemporaneous month as the return shock, while rebalancing in actively managed funds is stronger in the following month. These differences are consistent with index funds being more likely to be held by passive TDFs which rebalance faster and stick more closely to the mandated asset allocations, while active TDFs have more discretion in rebalancing.

For bond mutual funds, we also find that TDFs' rebalancing into bond funds when equity outperforms is passed on to the underlying fund level (in columns 4-6, $\widehat{\beta_{2}}$ and $\widehat{\beta_{4}}$ are positive). Consistent with the previous section, the flow effect of TDFs is stronger in the month following a return than in the contemporaneous month. But in contrast to equity funds, corporate bond fund flows rise when the equity market performs well $\left(\widehat{\beta_{1}}\right.$ and $\widehat{\beta_{3}}$ are generally positive). When equity outperforms bonds by $10 \%$ in a month, the average bond fund flow is $0.9 \%$ higher in the same month. This result is also true in the funds not held by TDFs (see Table A.7 columns 4-6). Therefore, unlike in equity markets, TDF flows are in the same direction as retail/institutional flows in the bond fund market (though TDF trades are slower), instead of trading against them.

We defer further discussions on bond fund flows to Section 7, where we explain why it may be difficult to identify a TDF effect on bond returns. ${ }^{19}$

\footnotetext{
${ }^{19}$ We also show in Table A.8 that TDFs have similar effects on foreign equity fund flows as on domestic equity fund flows.
} 


\subsection{TDFs reduce trend-chasing in aggregate equity fund flows}

Are fund-level TDF trades important for aggregate flows to mutual funds? using quarterly data to match the frequency of TDF tradings data, we calculate the aggregate dollar net flows to all domestic equity mutual funds as the sum of flows to both retail and institutional share classes. In cases where TDFs also invest in a retail or institutional share class, we deduct those TDF trades before taking the aggregate. We then calculate aggregate TDF trades in domestic equity funds.

Figure 4, panel A, shows that a positive excess return on the stock market in a quarter, $R^{E}-R^{B}$, is associated with increased inflows to domestic equity funds by retail and institutional investors in that same quarter. In contrast, as panel B of Figure 4 shows, aggregate TDF rebalancing trades move in the opposite direction as $R^{E}-R^{B}$ : high $R^{E}-R^{B}$ leads to significant outflows from domestic equity funds by TDFs. The different right-handside scales on the two panels differ by a factor of 10. Roughly, in aggregate, TDFs offset more than ten percent of all aggregate fluctuations in fund flows.

To be more precise, we calculate the share of aggregate return-chasing equity fund flows that are offset by TDF trading from regressions that account for the changing relative size of the two types of funds. We regress quarterly flows to domestic equity mutual funds (in percent) on current and lagged returns for three measures of flows: all aggregate retail and institutional flows (as a percent of all domestic mutual funds assets), total rebalancing flows from TDFs (as a percent of TDF assets), and all flows from TDFs (as a percent of TDF assets). We normalize the fund flows and TDF trades by their respective asset sizes because the TDF market grew at a much faster pace than the equity mutual fund sector during the period, as is somewhat visible in Figure 4. For each measure as the dependent variable, we estimate:

$$
\text { AggFlowPct } q=\gamma_{1}\left(R^{E}-R^{B}\right)_{q}+\gamma_{2}\left(R^{E}-R^{B}\right)_{q-1}+\delta+\epsilon_{q}
$$

and report the results in Table 5. Standard errors are estimated using the Huber-White heterokedasticity-consistent approach.

Table 5 shows that when the excess return, $R^{E}-R^{B}$, is $10 \%$, net aggregate flows to equity mutual funds through retail and institutional funds is higher by $0.9 \%$ of aggregate fund assets in the same quarter and higher by $0.3 \%$ in the following quarter (column 1 ). 
Meanwhile, TDFs sell 1\% of their lagged asset value in equity mutual funds (column 2).

Taking 2019 as our base year, the total asset size of domestic equity mutual funds is at $\$ 12$ trillion, and the total asset size managed by TDFs is at $\$ 1.4$ trillion. For a $10 \%$ excess performance of the equity market, retail and institutional flows are $\$ 108$ billion $(=12,000 \times 0.9 \%)$ higher than the baseline, but TDFs trade against the retail/institutional flows at the amount of $\$ 14$ billion $(=1,400 \times 1 \%)$, thereby offsetting about $13 \%$ of the trend-chasing tendency of retail/institutional flows in the same quarter as the realized asset class returns. This fraction is in line with that implied by Figure 4. Including trading in the subsequent quarter, TDF rebalancing trades offsets $21 \%(=1,400 \times 2 \%) /(12,000 \times 1.1 \%))$ of total retail/institutional flows. While these are large flows relative to the average flows associated with trend-chasing, these effects of these strategies are even larger if we assume that all $\$ 4$ trillion of TDF, CITs, and balanced funds rebalance in a similar way. Our estimates imply that in 2019 , these funds offset almost $40 \%$ of the aggregate mutual fund flows related to asset-class relative returns.

Column 3 of Table 5 examines the aggregate total trades of TDFs, which include any active movement by retail investors into and out of TDFs rather than just the TDFs' rebalancing trades. Including the investor flows makes aggregate trades by TDFs less contrarian in the concurrent quarter (largely due to the inflows into TDFs for young investors that coincide with strong equity market performance during our sample period) and more contrarian the following quarter, reducing the estimates' current quarter offset by two thirds and the cumulative offset by one fifth.

\section{TDF ownership and stock returns}

We now show that rebalancing by the TDF sector affects the returns on the stocks that TDFs hold disproportionately through the mutual funds they invest in. Specifically, stocks with higher TDF ownership exhibit lower "market momentum" or sensitivity to recent market performance. Note that our notion of market momentum is different from the cross-sectional momentum that is widely documented in the literature, which refers to the phenomenon that stocks that outperform in the cross-sectional are likely to continue 
outperforming in the medium term (as in Jegadeesh and Titman, 1993, 2001). ${ }^{20}$

We start by estimating the impact of TDFs on stock returns in Section 5.1, and then discuss the magnitude of the result and its context in Section 5.2. Section 5.3 conducts an index-inclusion study using only variation in TDF ownership driven by inclusion in the S\&P 500 index (the statistical significance of which is weak in a two-stage-least-squares estimate).

\subsection{Estimation of TDF effect at stock level}

Calculation of risk-adjusted return We estimate the TDF effect as a change in the sensitivity of the stock return to the differential asset class return $R^{E}-R^{B}$, which is similar to the concept of market beta, therefore, we focus on monthly factor-risk-adjusted returns as the main outcome variables. Making market-risk adjustment is necessary because TDFheld stocks tend to be large-cap stocks that have higher market beta, without an adjustment for which, the TDF-held stocks may show a spurious higher sensitivity to $R^{E}-R^{B}$ that has nothing to do with the effect of TDFs. ${ }^{21}$

We follow a seven-factor risk adjustment model, which includes Market-rf (the excess return of the total equity market over the risk-free rate), small-minus-big (SMB or the size factor), high-minus-low (HML or the value factor) (Fama and French, 1993), momentum (Carhart, 1997), liquidity (Pástor and Stambaugh, 2003), robust-minus-weak (RMW or the profitability factor), and conservative-minus-aggressive (CMA or the investment factor) (Fama and French, 2015). An issue with this risk adjustment is that TDF trading can directly affect the sensitivity of a stock's return to the performance of the market, that is, TDFs lower the market beta of stocks, which is the main effect we want to measure. To alleviate this problem, we estimate the factor betas using the period 1996-2005 which is before the PPA of 2006, so that the betas are (largely) free of TDF impact. However, using the pre-TDF window to calculate the intrinsic betas is not perfect if betas change over time. Therefore, we also show that our results are robust to using alphas estimated with 36-month rolling-window betas. ${ }^{22}$ We expect the results using the rolling-windows to be

\footnotetext{
${ }^{20}$ The concept of market momentum is more similar to the "time series momentum" documented in Moskowitz, Ooi, and Pedersen (2012).

${ }^{21}$ For this reason, characteristics-based return adjustments such as the DGTW (Daniel et al., 1997) method is not sufficient for our purpose. However, we fully control for the effects of stock characteristics as explained below.

${ }^{22}$ The calculation requires at least 24 observations in the rolling window. As Table A.1 panel B shows, both
} 
weaker, because TDFs can downward bias stocks' market betas relative to the systematic risk in the cash flows. Thus the alphas of TDF-held stocks may appear more correlated with the excess equity market return than otherwise. ${ }^{23}$ We winsorize the alphas at $1 \%$ and 99\% to account for the fat tails due to extreme movements unrelated to TDF trading.

Regression specification We estimate the impact of TDF trading on stock returns by running the following regression on monthly alphas from 2010 to 2018, a period with sizable and growing assets in TDFs:

$$
\begin{aligned}
& \text { Alpha }_{i m l}=\lambda_{1}\left(R^{E}-R^{B}\right)_{m} \times T D F_{i q-1}+\lambda_{2}\left(R^{E}-R^{B}\right)_{m-1} \times T D F_{i q-1}+\gamma T D F_{i q-1}+\xi X_{i m} \\
& +\delta_{1} X_{i m} \cdot\left(R^{E}-R^{B}\right)_{m}+\delta_{2} X_{i m} \cdot\left(R^{E}-R^{B}\right)_{m-1}+\text { Return }_{i m-1}+\text { Return }_{i, m-6} \text { to } m-2 \\
& +\theta_{m l}+\epsilon_{i m}
\end{aligned}
$$

where $i$ indexes the stocks, $m$ represents a month, and $l$ refers to the three-digit SIC industry classification. TDF ownership at the stock level (expressed in percentage) is calculated as $T D F_{i, q-1}=\Sigma_{j k} a_{i j, q-1} b_{j k, q-1}$ for stock $i$ in the lagged quarter $q-1$, where $a_{i j, q-1}$ is the fraction of stock $i$ held by mutual fund $j$ and $b_{j k, q-1}$ is the fraction of mutual fund $j$ held by TDF $k .\left(R^{E}-R^{B}\right)_{m}$ and $\left(R^{E}-R^{B}\right)_{m-1}$ represent the current and lagged months' excess return of equity over bonds. We hypothesize that $\lambda_{1}$ and $\lambda_{2}$ are negative. The analysis clusters the standard errors two-ways by time (year-month) and stock.

Because the holdings of passive and active TDFs are highly correlated at the stock level (Figure A.5), we can infer the different effects of passive and active TDFs only roughly from differences between $\lambda_{1}$ and $\lambda_{2}$. As noted, large passive TDFs mostly rebalance by the end of every day (the lag is a few hours), while other TDFs, especially the active ones, can take a month or two before restoring their target asset allocations (Table 3). Thus we conjecture that trading by active TDFs contributes more to $\lambda_{2}$, while $\lambda_{1}$ is more driven by passive TDFs.

Equation (5) identifies the effect of TDFs on stock returns from differences between the stock holdings of the TDF sector and the market portfolio. Table 6 shows some of this beta and alpha estimates obtained using the two measures are similar in mean and standard deviation. The mean alphas are positive, instead of close to zero, because we exclude the smallest stocks and penny stocks.

${ }^{23}$ We show in Table A.9 that the stocks that are later held by TDFs had higher market betas during the pre-TDF period, but in the post-period, the measured market betas of those stocks decreased significantly, while there is no significant change in the market betas of the low-TDF stocks. This "difference-in-differences" result is consistent with TDFs lowering the market betas. However, it is only suggestive because there could be many other reasons for this change. 
variation in TDF holdings based on stocks with above ("high-TDF") or below ("low-TDF") median TDF ownership in each cross section. Most characteristics differ significantly between these two groups. High-TDF stocks have lower raw return and higher market beta, thus, they have lower alphas. We also find that the high-TDF stocks have larger market capitalization, higher ownership by other mutual funds, and are more liquid, as shown by their higher trading volume and lower Amihud (2002) illiquidity. Turning to the stock fundamentals, high-TDF companies appear high-growth (higher market-to-book ratio, lower dividend yield, higher ROE, and have insignificantly higher investment).

These differences highlight the importance for controlling for the effect of characteristics on the stock return sensitivity to the excess equity market return, to mitigate concerns that our results on the different return sensitivity may be caused by the different characteristics rather than TDF rebalancing, for example, through mutual fund flow pressure (e.g., Coval and Stafford, 2007; Lou, 2012) or the lead-lag effect (Lo and MacKinlay, 1990). To do so, we include in $X_{i m}$ a full set of characteristics, including log of lagged market capitalization, trading volume, the market-to-book ratio, lagged trailing-twelve-month dividend yield, ROE, investment, illiquidity, and the holdings by mutual funds that are not held by TDFs. We further control for $R^{E}-R^{B}$ interacted with all characteristics. Our analysis also controls for the typical co-movement of stock returns within industries by including industry(3-digit SIC)-by-time fixed effects $\left(\theta_{m l}\right)$. Another concern is that our results may be related to the well-documented short-term phenomenon (see, e.g., Jegadeesh, 1990; Nagel, 2012), in the sense that if TDFs hold large-cap stocks that drive up $R^{E}$, the effect we estimate may simply capture these stocks' reversal. Therefore, we control for both short-term and medium-term lagged returns $\operatorname{Return}_{i m-1}$ and $\operatorname{Return}_{i, m-6}$ to $m-2$ (medium-term lagged return is to control for momentum).

Main results Table 7 shows that higher TDF ownership is associated with lower sensitivity to market momentum. Panel A uses the seven-factor alphas estimated with betas from the pre-TDF window as the dependent variable, and panel $B$ examines rollingwindow alphas. In panel A, column 1, a specification without controls, the coefficient on $\left(R^{E}-R^{B}\right)_{m} \times T D F_{i q-1}$ indicates that a one standard deviation $(0.7 \%)$ higher TDF ownership of a stock implies a $0.028(=0.7 \times 0.04)$ lower sensitivity of the 7 -factor alpha of that stock to the contemporaneous market return. That is, if the market rises by $1 \%$ in a month relative to bonds, a one standard deviation higher level of TDF ownership implies a 2.8 
basis point lower risk-adjusted return on that stock in the same month. In contrast, the coefficient on $\left(R^{E}-R^{B}\right)_{m-1} \times T D F_{i q-1}$ is small and insignificant in the current specification without control variables.

The concentration of the price effect in the contemporaneous month is consistent with the result from Table 3 that almost half of TDF rebalancing in equity (half for passive TDFs) occurs within the month contemporaneous with the asset-class returns. We find little price impact during the month after the return, when most rebalancing is done by active TDFs. One possible explanation is that active TDFs might change their portfolio composition in response to asset-class returns to reduce price impact. Another possibility is that front-running the predictable trades by active TDFs can move the price effect earlier.

When adding stock characteristics in column 2 as controls, the estimate becomes slightly stronger. In column 3, we further control for the stock return lagged by one month and the cumulative return from month $m-6$ to $m-2$ to account for both short-term reversal and medium-term momentum in the stock returns. We observe a strong negative coefficient on the one-month lagged return, consistent with the well-known reversal effect. However, controlling for lagged returns does not change our estimates of the TDF effect in the contemporaneous month. The addition of lagged returns as controls makes the estimated effect in the following month (possibly an active TDF effect) bigger in magnitude, though still not statistically significant, suggesting that the stocks indirectly traded by active TDFs in the following month tend to be less subject to short-term reversal after differential asset class shocks. Lastly, in column 4 , we include the full set of stock characteristics interacted with both $\left(R^{E}-R^{B}\right)_{m}$ and $\left(R^{E}-R^{B}\right)_{m-1}$. If our results are entirely driven by the different characteristics of TDF-held stocks, we should expect the main coefficients on the interaction terms between differential asset class returns and indirect TDF investment to go away. However, column 4 shows that adding the interactions with characteristics does not alter the estimated TDF effect, implying that the TDF effect is distinct from the potential effects of other stock characteristics on return dynamics.

We find similar results using rolling-window alphas as the dependent variable (Panel B of Table 7). The next-month effect, as shown by the coefficients on $\left(R^{E}-R^{B}\right)_{m-1} \times T D F_{i q-1}$, remains similar to those in panel $\mathrm{A}$, however, the same-month effect, or the coefficients on $\left(R^{E}-R^{B}\right)_{m} \times T D F_{i q-1}$, shrinks by about half. This is consistent with the fact that the behavior of TDFs changes the market betas of stocks and so the risk-adjustment biases 
down the estimated effect of TDFs. However, panel B confirms that the direction of the TDF effect remains robust with marginal statistical significance under the alternative measurement of alpha.

Falsification test and robustness As another approach to checking whether these results are indeed driven by the trading of TDFs, we conduct falsification tests using an earlier period 1987-2005, i.e., before the PPA of 2006 set off the growth of the TDF (and balanced funds) market. ${ }^{24}$ Using TDF ownership measured as the average during 2010-2018, we conduct our falsification analysis in the earlier period. The result, presented in columns 5 in both panels, suggests that stocks that would have high TDF ownership in the most recent period did not have lower market momentum before the PPA. While the rise of TDFs is not the only change that occurred in financial markets over this period and so other factors may influence the differences between the pre-TDF and post-TDF periods, these results show that the results documented in Table 7 are unique to the TDF era.

We conducted two additional analyses that support the main results in Table 7. First, we break down the results into two sub-periods: 2010-2014 and 2015-2018. TDFs (and other rebalancing strategies) grow substantially in size from the first to the second period. As expected, the estimate of the TDF effect with pre-window alphas appears slightly stronger in the later period, though the power is low for this test and the result with rolling-window alphas is weak in both periods (Table A.10). Second, we show that actual TDF rebalancing has price impact by studying the price response to quarterly stock-level rebalancing by TDFs instead of that predicted by their lagged holdings. We allocate the TDF rebalancing trades to stocks through mutual funds and find that these more endogenous trades by TDFs also impact quarterly risk-adjusted stock returns (Table A.11). Because these rebalancing trades by TDFs are in part driven by their discretionary strategies that may be endogenous to expected stock returns, we continue to focus on TDF ownership (instead of the trades themselves).

\subsection{Quantitative significance}

Using the estimated price effect in Table 7, panel A, (the average coefficient -0.04 on $\left.R^{E}-R^{B}, t \times T D F(\%)\right)$, and scaling the $T D F(\%)$ by a factor of four to account for all TDFs,

\footnotetext{
${ }^{24}$ The choice of 1987 as the beginning of the period used for the falsification test is that our measure of $R^{B}$, based on returns of the Vanguard Total Bond Market Index Fund, is only available starting then.
} 
balanced funds, and CITs, we estimate a demand elasticity of -0.3 (details in Appendix C). That is, when these funds purchase an additional $1 \%$ of a stock's market capitalization, the price of that stock rises by $3 \%$. Note that in this calculation we are assuming that the holdings of balanced funds and CITs are proportional to those of TDFs. As discussed in Section 1, most CITs have almost identical portfolios to a corresponding TDF, and many TDFs merge into balanced funds when they reach the target retirement dates. However, there are wide variety of balanced funds, and in this sense, our assumption is quite strong.

In the remainder of this subsection, we discuss several other types of fixed-share funds that may hold similar stocks as TDFs. If our estimated price response are in part driven by the rebalancing behavior of these market contrarian traders as well as TDFs, then stock prices would be less responsive than our estimate of -0.3 implies.

Model portfolios Model portfolios, which have grown considerably in the last decade, are managed portfolios that mainly invest in mutual funds and exchange-traded funds following predefined asset allocations. Broadridge (2019) describes the three segments of the model portfolios market, i) robo-advisors, ii) mutual fund advisory programs driven by financial advisors seeking to improve efficiency and broker-dealer home offices pushing their brand of centralized decision-making, and iii) mutual fund companies as strategists and model platforms. Like TDFs, model portfolios have features of fixed allocations and automatic rebalancing in response to market conditions. ${ }^{25}$ Broadridge estimates assets in model portfolios to be $\$ 4$ trillion in 2019 (Lim, 2020). Given the similarity in investment objectives and overlap in sponsors, there may be high correlation between holdings of the model portfolios and TDFs at the stock level. The rebalancing speed may also be similar. For example, when BlackRock adjusted its model portfolios in 2021, the underlying funds (ETFs) experience massive flows within a week (Lim, 2021). Therefore, the actions of model portfolios may have substantial overlap with those of TDFs at the stock level.

Hedge funds The global hedge fund industry has \$ 4 trillion AUM in 2021. The majority of strategies do not appear similar to those of TDFs. Grinblatt et al. (2020) examines hedge funds with Form 13-F filings of stock holdings and finds that about two thirds of the hedge funds engage in cross-sectional contrarian strategies, which are different from the market-contrarian trades of the TDFs. However, some hedge funds also engage in "risk

\footnotetext{
${ }^{25}$ For example, Morningstar (2021) indicates that the vast majority of model portfolios follow allocation strategies, where the most common equity share is between $50 \%$ and $70 \%$.
} 
parity" strategies that maintain a desired risk level (though there is not an explicit target asset allocation).

Pension funds and endowments Pension funds, foundations, family offices and endowments often specify target allocations as part of their investment objectives, which indicates they also need to periodically rebalance. However, these funds are typically much slower to rebalance, often have more discretion over the target allocations, and in general are given much greater flexibility (Andonov and Rauh (2020)). Overall, it seems most likely that the rebalancing of pensions and endowments contributes to the aggregate contrarian fund flows but at a much lower frequency.

In addition to underestimating total rebalancing flows, our estimated price elasticity is context-specific and may be large for the following reasons. First, TDFs typically do not disclose their trading schedule to avoid strategic trading around their rebalancing. As we show in Section 3.3, while the rebalancing by TDFs fits their stated objectives, there is significant variation at the TDF level, which can lead to large uncertainty regarding both the timing and the amount of their trades and make it risky to front-run TDFs. ${ }^{26}$ Second, we are looking at systematic changes in demand for a set of similar stocks. ${ }^{27}$ Therefore, if there were profits to front-running TDFs, equity traders would have to bear systematic risk to profit from trading before the TDF price impact. Lastly, as we will show below, trading against TDFs to reduce the price movements is not a profitable trade.

\subsection{Evidence from S\&P 500 index inclusion}

In this section, we focus on a narrow source of variation in TDF ownership that can provide some plausibly exogenous variation: inclusion in the S\&P 500 index. We first show that active TDFs have a preference to hold S\&P 500 index funds while passive TDFs are more likely to hold the total market. We then identify the price impact of (active) TDFs only from variation in holdings by TDFs that is driven by index inclusion.

We construct a group of control stocks for stocks in the S\&P 500, following the methodology in Denis et al. (2003), the details of which are presented in Appendix D. To measure

\footnotetext{
${ }^{26}$ In a more predictable setting around dividend re-investment, Hartzmark and Solomon (2021) finds slightly smaller price effect.

${ }^{27}$ In this sense, our estimate may be on the same order of magnitude as the estimates of asset-class level demand elasticity (see, e.g., Da et al., 2018; Gabaix and Koijen, 2020).
} 
the extent to which TDFs overweight S\&P 500 stocks, we estimate the following stock-level regression using quarterly data on the matched sample of S\&P 500 stocks and their controls:

$$
T D F(\%)_{i p q}=\beta S \& P 500_{i q}+\lambda X_{i q}+\theta_{p q}+\alpha_{i}+\epsilon_{i p q}
$$

where $p$ indexes the peer groups that contain "similar" stocks, the dependent variable is stock-level indirect TDF ownership expressed in percentages, S\&P 500 is an indicator $\in\{0,1\}$ for being included in the S\&P 500. We include as control variables, $X_{i q}$, market capitalization, trading volume, the market-to-book ratio, dividend yield, profitability, investment, illiquidity, ownership by mutual funds without TDF investments, and the quarterly return of the stock. The matched-peer-group by quarter fixed effects $\theta_{p t}$ imply that the result comes from comparing stocks in and out of the S\&P 500 index in that quarter conditional on industry, size, and liquidity. ${ }^{28}$

Table 8 shows that being included in the S\&P 500 index is associated with $0.21 \%$ higher TDF ownership (or about one-third of the mean), relative to similar stocks that are not included in the index (column 1). This effect is primarily due to holdings of index funds (column 2) and primarily driven by active TDFs (comparing columns 4 and 5), although the effect only through actively managed funds is (economically similar but) imprecisely estimated (column 3). ${ }^{29}$

We then estimate how individual stock returns vary both with market-level excess returns and inclusion in the S\&P index, using the following regression:

$$
\begin{gathered}
\text { Alpha }_{i p m}=\gamma_{1}\left(R^{E}-R^{B}\right)_{m} \times S \& P 500_{i m}+\gamma_{2}\left(R^{E}-R^{B}\right)_{m-1} \times S \& P 500_{i m} \\
+\eta S \& P 500_{i m}+\xi X_{i m}+\delta_{1} X_{i m} \cdot\left(R^{E}-R^{B}\right)_{m}+\delta_{2} X_{i m} \cdot\left(R^{E}-R^{B}\right)_{m-1}+\theta_{p m} \\
\psi_{i}+\text { Return }_{i m-1}+\text { Return }_{i, m-6} \text { to } m-2+\epsilon_{i p m}
\end{gathered}
$$

where $p$ index peer group and $m$ month and again, $\theta_{p m}$ is the key fixed effect that implies

\footnotetext{
${ }^{28}$ We include stock fixed effects $\alpha_{i}$, so that we only exploit the variations from stocks that are included in the index in some periods during the sample. Stocks that are always included in or excluded from the index do not affect our estimate.

${ }^{29}$ These patterns are consistent with the strategies of large passive and active TDFs, and that many active TDFs, such as T. Rowe Price, hold the S\&P 500 index fund as a large building block in their equity portfolios (in addition to actively managed equity funds). While the largest passive TDFs use total market index funds for their equity allocations, the TDF sector historically over-weighted the S\&P, especially early in our sample. See Figure A.6.
} 
that we are only comparing stocks within their peer group, and $\psi_{i}$ is stock fixed effect. $S \& P 500_{i m}$ equals one if a stock is included in the S\&P 500 index in month $m$, and zero otherwise. Equation (7) estimates the key coefficients $\gamma_{1}$ and $\gamma_{2}$ from a difference-indifferences type specification that compares, within each peer group, the responses to market return of $i$ ) the return on stocks included in the S\&P 500 index which have higher TDF ownership, to $i$ ) the return on stocks not included in the index which have lower TDF ownership. Note that Table D.1 shows that even with the construction of the peer groups, we cannot match the characteristics of stocks in and out of the S\&P. Therefore, we control for the full set of characteristics interacted with both current and lagged $R^{E}-R^{B}$. Lastly, we include lagged returns to control for short-term reversals.

Table 9 shows that when the market rises by $1 \%$ in a month, stocks that are included in the S\&P 500 index have lower risk-adjusted returns in both the contemporaneous month and the following month, though the statistical significance is higher in the following month, consistent with the speed of rebalancing by active TDFs that have a larger holding of S\&P 500 index funds. ${ }^{30}$

To evaluate the economic and statistical significance of TDF ownership directly, we estimate a two-stage least squares regression in which we estimate how TDF ownership interacts with market momentum - as in our main results in Table 7 - but using only variation in TDF ownership driven by inclusion in the S\&P 500 index. We relegate the complete description of this analysis to Appendix D because nothing is statistically significant (See Table D.2). In sum, while the evidence in this section identifies prices effects using only the more exogenous variation in TDF ownership share driven by S\&P inclusion, it is statistically weak. As such, it provides at best evidence that the market-contrarian trading strategies of TDFs have changed the price dynamics of the stocks they hold.

\footnotetext{
${ }^{30}$ Previous research has documented other features of stock dynamics that change when a stock when is included in a major index, including but not limited to price increase (Harris and Gurel, 1986; Shleifer, 1986; Wurgler and Zhuravskaya, 2002; Chang, Hong, and Liskovich, 2015), excess daily return volatility (Ben-David, Franzoni, and Moussawi (2018)), and co-movement (Barberis, Shleifer, and Wurgler, 2005; Boyer, 2011). None of these effects would seem to contaminate or bias our estimate of the price impact of TDFs associated with S\&P index inclusion, although we discuss them further in Appendix D.
} 


\section{Returns from trading before or with TDFs}

This section presents evidence that during our sample period, trading that mitigates the TDF price impact was not profitable. In fact, because retail investors move money into equity funds in response to excess returns on the stock market, if arbitrage capital trades against these general retail/institutional flows, they trade in the same direction as the contrarian trading by TDFs. Thus the cross-sectional price impact of TDF trading that we find may be large relative to other situations where arbitrage capital may be trading against the price impact.

Based on our findings in Section 5, we consider two long-short monthly strategies, one that (infeasibly) trades at the start of the month before an aggregate return and the contemporaneous TDFs rebalancing, and one that trades alongside slower TDF rebalancing in the month following the return. Because stocks high in TDF investments have lower returns during and after high equity market performance, these strategies short high-TDF stocks and buy low-TDF stocks when the equity market return is high and take the opposite position when the market is low. In each quarter and within each size group based on market capitalization (the size groups are defined according to NYSE size breakpoints that are at 5-percentile increments), we sort stocks into quintiles based on (non-TDF) mutual fund ownership, and then within each mutual fund quintile, sort again based on TDF ownership. ${ }^{31}$ We then form portfolios every month based on the sign of the excess equity market return and the predicted direction of TDF trades.

First, consider a strategy that takes its position prior to the asset class return during a month: if $\left(R^{E}-R^{B}\right)_{m}<0$, it goes long the highest TDF quintile of stocks and shorts the lowest TDF quintile at the beginning of month $m$ and holds until the end of the month. If $\left(R^{E}-R^{B}\right)_{m}>0$, the strategy takes the opposite long-short position. This strategy frontruns TDFs but is infeasible because it requires predicting aggregate return shocks and risky because the timing and magnitude of TDF rebalancing is uncertain. Figure 5 panel A shows that the cumulative risk-adjusted return of this strategy. Either equal-weighting or market-cap-weighting stocks (solid line or dashed line) produces a steady positive riskadjusted return that amounts to a cumulative 60\% return in the period we plot (2010-2018), or about 50 bps per month on average. This is an (infeasible) upper bound to the profit of

\footnotetext{
${ }^{31}$ To avoid our results being driven by a few stocks, we drop cells where the numbers of observations are lower than five. The trading profits are smaller and noisier if we do not exclude those cells.
} 
front-running.

Second, the feasible strategy that trades along with TFDs is based on the previous month's return: if $\left(R^{E}-R^{B}\right)_{m-1}>0$, go long the highest TDF quintile of stocks and short the lowest quintile during month $m$, and the reverse when $\left(R^{E}-R^{B}\right)_{m-1}<0$. Because this strategy trades the month after a return, it is presumably mainly trading alongside active TDFs which are slower to rebalance. Panel B of Figure 5 shows that this feasible strategy of trading along with TDFs still generates positive profits but is less profitable. Most importantly, the reverse of this second strategy would have generated a loss of $20 \%-40 \%$ return over nine years depending on the weighting scheme. In sum, it does not seem to be profitable to trade against TDFs based on the previous month return, so arbitrage capital should not be reducing the cross-sectional price impact of TDF trading. ${ }^{32}$

Finally, we investigate how long the price impact of TDF contrarian trading lasts. We estimate the following equation with the dependent variable at increasing horizons and plot the effect of TDF contrarian rebalancing on prices at different horizons.

$$
\begin{gathered}
\text { Cum.alpha }_{i m l h}=\lambda_{h}\left(R^{E}-R^{B}\right)_{m} \times T D F_{i q-1}+\gamma_{h} T D F_{i q-1}+\xi_{h} X_{i m}+\delta_{h} X_{i m} \cdot\left(R^{E}-R^{B}\right)_{m} \\
+ \text { Return }_{i m-1}+\text { Return }_{i, m-6} \text { to } m-2+\theta_{m l}+\epsilon_{i m h}
\end{gathered}
$$

where $i$ indexes the stocks, $m$ represents the month of the differential asset-class shock, $l$ refers to the three-digit SIC industry classification, and $h$ indicates the horizon of the cumulative return. $\left(R^{E}-R^{B}\right)_{m}$ represents the current months' excess return of equity over bonds. $T D F_{i q-1}$ is the indirect TDF ownership at the stock level at the end of the previous quarter. As in the full specification in Table 7, the estimations control for a full set of stock characteristics interacted with $\left(R^{E}-R^{B}\right)_{m}$. The regressions also control for raw return in month $m-1$, and cumulative raw return from month $m-6$ to month $m-2$ and include industry-by-time fixed effects $\left(\theta_{m l}\right)$.

Figure 6 plots the estimated coefficients $\widehat{\lambda_{h}}$ as a function of horizon $h$ and shows that the cumulative price impact is largest at the end of the month after the (monthly) asset-class return. The effect on cumulative returns lasts for about three months before becoming

\footnotetext{
${ }^{32}$ Table A.12 shows that the trading profits are statistically significant. We also show in Figure A.7 that a simple contrarian strategy that buys the total market after $\left(R^{E}-R^{B}\right)_{m-1}<0$ and shorts the market vice versa does not generate a steady positive profit during our period. This suggests that exploiting cross-sectional TDF trades is important for generating the trading profit.
} 
indistinguishable from zero. Overall, evidence in Figure 6 is consistent with limited or slow arbitrage of price impact that is tempered by additional trading by (mainly active) TDFs in the months following a return shock.

\section{TDFs and bond returns}

In Section 3, we find that TDFs rebalance into bond funds (while selling equity) when $R^{E}-R^{B}>0$, and vice versa. The magnitude of the trade with respect to bonds is smaller and the speed slower than that with equities. To manage any potential price impact, TDFs often use cash and derivatives to rebalance their fixed income exposure before trading these funds. In Section 4, we showed that the rebalancing by TDFs have an expected effect on the flows to bond funds that they hold in the month following the differential asset class return shock. In this section, we show that TDF trading does not appear to causes price impact for corporate bonds that have relatively higher TDF exposure, which we conjecture is due to liquidity management strategies.

We focus on the corporate bond market because almost $70 \%$ of $\mathrm{TDFs}^{\prime}$ holdings of bond funds are in corporate bond funds (Table A.13). One might expect a larger price impact in the corporate bond market becuase it is less liquid than the stock market. Also, as noted earlier, rebalancing trades by TDFs with respect to bond funds are in the same direction as the general retail and institutional flows, potentially implying greater price impact. However, since both TDFs and the underlying bond mutual funds might expect this illiquidity, they might manage liquidity in a way to minimize the price impact. ${ }^{33}$ In addition, arbitrageurs, trading against retail flows, would be trading against TDFs in the case of bonds.

To begin, we examine characteristics of both bond funds and corporate bonds that have different levels of TDF investment (Appendix E explains the construction of the samples of bond funds and corporate bonds, following Choi et al. (2020)). Panel A of Table 10 shows selected summary statistics on corporate bond funds with above-median, below-median, or zero TDF investment. First, corporate bond funds with higher TDF investment also hold more cash or cash-like securities. The cash ratio is $17 \%$ for the funds with above-median

\footnotetext{
${ }^{33}$ Choi et al. (2020) shows how corporate bond funds use cash cushions to avoid price impact in response to investor redemptions. And Ma, Xiao, and Zeng (forthcoming) shows how bond mutual funds follow a pecking order by trading the most liquid assets first.
} 
TDF investment, and $12 \%(11 \%)$ for those with low (zero) TDF investment. This suggests that TDFs selectively hold corporate bond funds that strategically manage liquidity and maintain a bigger cash buffer against redemption risk. Second, funds that are invested more by TDFs also hold higher-rated corporate bonds, suggesting more TDF investments in safer and more liquid bonds. Turning to the bonds themselves in panel B of Table 10, TDF-held corporate bonds have higher rating, lower raw return, and longer time to maturity. In addition, TDFs choose to tilt their holding to bonds that are more liquid, as suggested by lower Roll (1984) illiquidity measure and smaller fraction of zero-trading days in a quarter.

In Appendix E (Table E.1), we present a study of the effect of TDFs on corporate bond returns in a sample of bonds with beginning-of-month rating in the top three categories, i.e., numerical ratings 1-3, equivalent to $\mathrm{S} \& \mathrm{P}$ ratings $\mathrm{AAA}, \mathrm{AA}+$, and $\mathrm{AA}$. This choice is motivated both by the fact that TDFs tend to hold bonds with higher ratings and by the pecking order funds follow to trade their holdings based on liquidity ( $\mathrm{Ma}, \mathrm{Xiao}$, and Zeng (forthcoming)). Though the estimated coefficients are in the expected direction as TDF trading, overall we cannot detect a significant effect of TDFs on corporate bond returns, a result in line with ex ante liquidity management reducing potential price impact.

\section{Speculation about aggregate market dynamics}

The goal of our paper is to document that the growth of TDFs and similar funds and strategies - designed to be micro-optimal taking returns as given - has an impact on mutual fund flows and on stock returns. This section discusses three potential aggregate market implications of continued movement of retail investor funds into TDFs and TDF-like strategies.

First, by putting downward pressure on prices after market increases and upward pressure after market drops, contrarian strategies dampen market fluctuations. Suppose $R^{E}-R^{B}=10 \%$ in a period, at the current holdings of $4 \%$ of the U.S. equity market (Figure A.8), TDFs, CIs, and balance funds trade $-0.12 \%$ of the market $(=-.7 * .3 * 10 \% *$ $4 \% / .7$ ), assuming they have an effective average desired equity share of $70 \%$. Even if we aggressively assume that all rebalancing is implemented within the same period and an aggregate "price multiplier" is 5 (Gabaix and Koijen (2020)), these trades would reduce 
the excess equity return by $0.6 \%$, or from $10 \%$ to $9.4 \%$, which is statistically undetectable (given the sample size to date). However, if stocks held by rebalancing investors were to grow to $20 \%$ of the market, the return would be reduced by $30 \%$ (from $10 \%$ to $7 \%$ ).

This dampening can either decrease or increase market efficiency. By trading against transitory fluctuations in prices, funds like TDFs may increase market efficiency. However, TDFs also trade against market fluctuations that are driven by permanent changes in dividends, which (roughly) should lead to permanent changes in the effective amount of equity relative to bonds. Since TDFs have a micro-optimal view of portfolio choice, TDFs do not adjust equity shares to permanent changes in the fraction of the market portfolio composed of different asset classes. If TDFs instead held a macro-optimal view of portfolio choice, they would hold the market portfolio and a risk-free asset in agedependent proportions and thus hold more equity when equity comprised more of the market portfolio.

Second, TDFs can generate a negative autocorrelation at horizons that match the time interval between price changes and the completion of rebalancing. We find that the majority of TDFs' rebalancing occurs in the contemporaneous month but also a substantial amount the following month. At the aggregate level, this rebalancing could alter serial correlation in monthly returns.

$$
r_{m}=\alpha+\beta_{1} r_{m-1}+\beta_{2} r_{m-1} \times T D(B) F_{y-1}+\gamma T D(B) F_{y-1}+\epsilon_{m}
$$

where $r_{m}$ is the monthly return of the U.S. equity market in month $m$, either as the raw return or as the excess return relative to the U.S. bond market, and $T D(B) F_{y-1}$ measures the fraction of the market held by TDFs, CITs, and BFs at the end of the previous year. ${ }^{34}$

The results in Table 11 suggest that the rise of TDFs has been accompanied by a reduction in the aggregate momentum or an increase in stock market reversal. Consistent with recent figures, if TDFs (and similar funds) controlled $4 \%$ of the market, the implied autocorrelation would be $0.29-9 * 4 \%=-0.07$, but statistical power is relatively low given the short time series. Further, the rise of TDFs is far from the only change in equity markets that may change the autocorrelation of returns (e.g. see Martin, 2021).

Finally, because TDFs increase linkages across asset classes, their continued growth may

\footnotetext{
${ }^{34}$ Some specifications rely on the total ownership of TDFs, and the size of CITs are only available yearly.
} 
increase the correlations between stock and bond returns. Interest rate declines - such as pursued by quantitative easing - may lead to stronger stock market responses, as an increasingly large amount of funds invested in TDFs trades out of bonds and into stocks.

Of course all of these speculative points may be mediated by endogenous changes in trading behavior of other market participants. The responses, and the general equilibrium effects, may provide interesting fodder for testing models of asset price dynamics.

\section{Concluding remarks}

Target date funds are an important financial innovation for retail investors. Since the 2006 Pension Protection Act qualified TDFs to serve as default options in 401(k) plans, the TDF market has experienced substantial growth. Today $90 \%$ of employers offer TDFs as the default options in their retirement plans and TDFs manage trillions of dollars of retirement savings. Retail investors that invest in TDFs do not have to choose the relative shares of stock funds and bond funds in their portfolios. Instead, they delegate these choices to TDFs that make these allocations based on automatic, age-dependent rules designed by professional money management companies. As a result, many retirement plan investors have moved from passive or trend-chasing behavior to investment vehicles that automatically rebalance their portfolios across asset classes to undo compositional changes due to differences in returns across asset classes.

This paper points to a quantitatively important implication of the rise of this household finance innovation for the dynamics of asset markets. TDFs rebalance portfolios by selling stocks when the stock market rises and buying stocks when the market falls, and so act as a market-stabilizing force. We find that in the past 15 years, the growth of TDFs has changed the patterns of fund flows across mutual funds and the cross-sectional pattern of returns across stocks. In addition, we speculate that if the amount of funds invested through TDFs continues to grow, the contrarian trading of these types of funds will start to have noticeable effects on aggregate market returns. 


\section{References}

Agnew, J., P. Balduzzi, and A. Sunden. 2003. Portfolio choice and trading in a large 401 (k) plan. American Economic Review 93:193-215.

Ameriks, J., and S. P. Zeldes. 2004. How do household portfolio shares vary with age? .

Amihud, Y. 2002. Illiquidity and stock returns: cross-section and time-series effects. Journal of Financial Markets 5:31-56.

Andonov, A., and J. D. Rauh. 2020. The return expectations of institutional investors .

Balduzzi, P., and J. Reuter. 2019. Heterogeneity in target date funds: strategic risk-taking or risk matching? The Review of Financial Studies 32:300-37.

Barberis, N., A. Shleifer, and J. Wurgler. 2005. Comovement. Journal of financial economics 75:283-317.

Ben-David, I., F. Franzoni, and R. Moussawi. 2018. Do etfs increase volatility? The Journal of Finance 73:2471-535.

Ben-David, I., J. Li, A. Rossi, and Y. Song. 2021. Discontinued positive feedback trading and the decline in asset pricing factor profitability. working paper, available at SSRN 3808853 .

- forthcoming. What do mutual fund investors really care about? The Review of Financial Studies .

Ben-Rephael, A., S. Kandel, and A. Wohl. 2011. The price pressure of aggregate mutual fund flows. Journal of Financial and Quantitative Analysis 585-603.

Bhattacharya, U., J. H. Lee, and V. K. Pool. 2013. Conflicting family values in mutual fund families. The Journal of Finance 68:173-200.

Boyer, B. H. 2011. Style-related comovement: Fundamentals or labels? The Journal of Finance 66:307-32.

Boyson, N. 2019. The worst of both worlds? dual-registered investment advisers. working paper, Northeastern University .

Broadridge. 2019. The rise of model portfolios.

Brown, D. C., and S. Davies. 2020. Off target: On the underperformance of target-date funds. Available at SSRN 3707755 .

Calvet, L. E., J. Y. Campbell, and P. Sodini. 2009. Fight or flight? portfolio rebalancing by individual investors. The Quarterly Journal of Economics 124:301-48.

Campbell, J. Y. 2016. Restoring rational choice: The challenge of consumer financial regulation. American Economic Review: Papers \& Proceedings 106:1-30. 
Carhart, M. M. 1997. On persistence in mutual fund performance. The Journal of Finance 52:57-82.

Chalmers, J., and J. Reuter. 2020. Is conflicted investment advice better than no advice? Journal of Financial Economics .

Chang, Y.-C., H. Hong, and I. Liskovich. 2015. Regression discontinuity and the price effects of stock market indexing. The Review of Financial Studies 28:212-46.

Chen, Y., and N. Qin. 2017. The behavior of investor flows in corporate bond mutual funds. Management Science 63:1365-81.

Choi, J., S. Hoseinzade, S. S. Shin, and H. Tehranian. 2020. Corporate bond mutual funds and asset fire sales. Journal of Financial Economics 138:432-57.

Cocco, J. F., F. J. Gomes, and P. J. Maenhout. 2005. Consumption and portfolio choice over the life cycle. The Review of Financial Studies 18:491-533.

Coval, J., and E. Stafford. 2007. Asset fire sales (and purchases) in equity markets. Journal of Financial Economics 86:479-512.

Da, Z., B. Larrain, C. Sialm, and J. Tessada. 2018. Destabilizing financial advice: Evidence from pension fund reallocations. The Review of Financial Studies 31:3720-55.

Daniel, K., M. Grinblatt, S. Titman, and R. Wermers. 1997. Measuring mutual fund performance with characteristic-based benchmarks. The Journal of finance 52:1035-58.

De Long, J. B., A. Shleifer, L. H. Summers, and R. J. Waldmann. 1990. Positive feedback investment strategies and destabilizing rational speculation. The Journal of Finance 45:37995.

Denis, D. K., J. J. McConnell, A. V. Ovtchinnikov, and Y. Yu. 2003. S\&p 500 index additions and earnings expectations. The Journal of Finance 58:1821-40.

Dou, W., L. Kogan, and W. Wu. 2020. Common fund flows: Flow hedging and factor pricing. Jacobs Levy Equity Management Center for Quantitative Financial Research Paper.

Duarte, V., J. Fonseca, A. Goodman, and J. A. Parker. 2021. Simple allocation rules and optimal portfolio choice over the lifecycle. NBER Working Paper w29559.

Edelen, R. M., and J. B. Warner. 2001. Aggregate price effects of institutional trading: a study of mutual fund flow and market returns. Journal of Financial Economics 59:195-220.

Evans, R. B., and Y. Sun. 2021. Models or stars: The role of asset pricing models and heuristics in investor risk adjustment. The Review of Financial Studies .

Fama, E. F., and K. R. French. 1993. Common risk factors in the returns on stocks and bonds. Journal of Financial Economics 33:3-56.

2015. A five-factor asset pricing model. Journal of Financial Economics 116:1-22. 
Frazzini, A., and O. A. Lamont. 2008. Dumb money: Mutual fund flows and the crosssection of stock returns. Journal of Financial Economics 88:299-322.

Gabaix, X., and R. S. Koijen. 2020. In search of the origins of financial fluctuations: the inelastic markets hypothesis. Available at SSRN .

Goldstein, I., H. Jiang, and D. T. Ng. 2017. Investor flows and fragility in corporate bond funds. Journal of Financial Economics 126:592-613.

Grinblatt, M., G. Jostova, L. Petrasek, and A. Philipov. 2020. Style and skill: Hedge funds, mutual funds, and momentum. Management Science 66:5505-31.

Haddad, V., P. Huebner, and E. Loualiche. 2021. How competitive is the stock market? theory, evidence from portfolios, and implications for the rise of passive investing. working paper, University of Minnesota .

Harris, L., and E. Gurel. 1986. Price and volume effects associated with changes in the s\&p 500 list: New evidence for the existence of price pressures. The Journal of Finance 41:815-29.

Hartzmark, S. M., and D. H. Solomon. 2021. Predictable price pressure. Available at SSRN 3853096 .

Hong, H., and J. C. Stein. 1999. A unified theory of underreaction, momentum trading, and overreaction in asset markets. The Journal of Finance 54:2143-84.

Investment Company Institute. 2022. Investment company fact book. Investment Company Institute, Washington, DC.

Jegadeesh, N. 1990. Evidence of predictable behavior of security returns. The Journal of finance 45:881-98.

Jegadeesh, N., and S. Titman. 1993. Returns to buying winners and selling losers: Implications for stock market efficiency. The Journal of Finance 48:65-91.

- 2001. Profitability of momentum strategies: An evaluation of alternative explanations. The Journal of Finance 56:699-720.

Koijen, R. S., and M. Yogo. 2019. A demand system approach to asset pricing. Journal of Political Economy 127:1475-515.

Lim, D. 2020. Model portfolios surging as advisers seek quick ways to invest client money .

_ 2021. Blackrock tweaked some models. it triggered a wave of buying and selling .

Lo, A. W., and A. C. MacKinlay. 1990. When are contrarian profits due to stock market overreaction? The review of financial studies 3:175-205.

Lou, D. 2012. A flow-based explanation for return predictability. The Review of Financial Studies 25:3457-89. 
Ma, Y., K. Xiao, and Y. Zeng. forthcoming. Mutual fund liquidity transformation and reverse flight to liquidity. The Review of Financial Studies .

Martin, I. 2021. On the autocorrelation of the stock market. Journal of Financial Econometrics 19:39-52.

Massa, M., R. Moussawi, and A. Simonov. 2020. The unintended consequences of investing for the long run: Evidence from the target date funds. Available at SSRN 3729750 .

Merton, R. C. 1969. Lifetime portfolio selection under uncertainty: The continuous-time case. The Review of Economics and Statistics 247-57.

Mitchell, O. S., and S. Utkus. 2021. Target date funds and portfolio choice in 401(k) plans. Journal of Pension Economics and Finance 1-18.

Morningstar. 2021. 2021 model portfolio landscape.

- 2022. 2022 target-date strategy landscape .

Moskowitz, T. J., Y. H. Ooi, and L. H. Pedersen. 2012. Time series momentum. Journal of Financial Economics 104:228-50.

Nagel, S. 2012. Evaporating liquidity. The Review of Financial Studies 25:2005-39.

Parker, J. A., A. Schoar, A. T. Cole, and D. Simester. 2022. Household portfolios and retirement saving over the life cycle. NBER Working Paper, W29881.

Pástor, L., and R. F. Stambaugh. 2003. Liquidity risk and expected stock returns. Journal of Political economy 111:642-85.

Peng, C., and C. Wang. 2021. Factor demand and factor returns. working paper, available at SSRN 3327849 .

Roll, R. 1984. A simple implicit measure of the effective bid-ask spread in an efficient market. The Journal of Finance 39:1127-39.

Schwarz, C. G., and M. E. Potter. 2016. Revisiting mutual fund portfolio disclosure. The Review of Financial Studies 29:3519-44.

Shleifer, A. 1986. Do demand curves for stocks slope down? The Journal of Finance 41:579-90.

Shoven, J. B., and D. B. Walton. 2020. An analysis of the performance of target date funds. NBER Working Paper, W27971.

Vayanos, D., and P. Woolley. 2013. An institutional theory of momentum and reversal. The Review of Financial Studies 26:1087-145.

Viceira, L. M. 2001. Optimal portfolio choice for long-horizon investors with nontradable labor income. The Journal of Finance 56:433-70. 
Warther, V. A. 1995. Aggregate mutual fund flows and security returns. Journal of Financial Economics 39:209-35.

Wurgler, J., and E. Zhuravskaya. 2002. Does arbitrage flatten demand curves for stocks? The Journal of Business 75:583-608. 
Figure 1: Size of assets in TDFs, target date CITs, and balanced funds by year

This figure plots the sum of total net assets (TNA) of target date funds (TDFs), target date collective investment trusts (CITs) and balanced funds (BFs) during 2000Q1-2021Q4. Assets in TDFs and BFs are estimated using CRSP. Assets in CITs are collected from annual Morningstar TDF research reports.

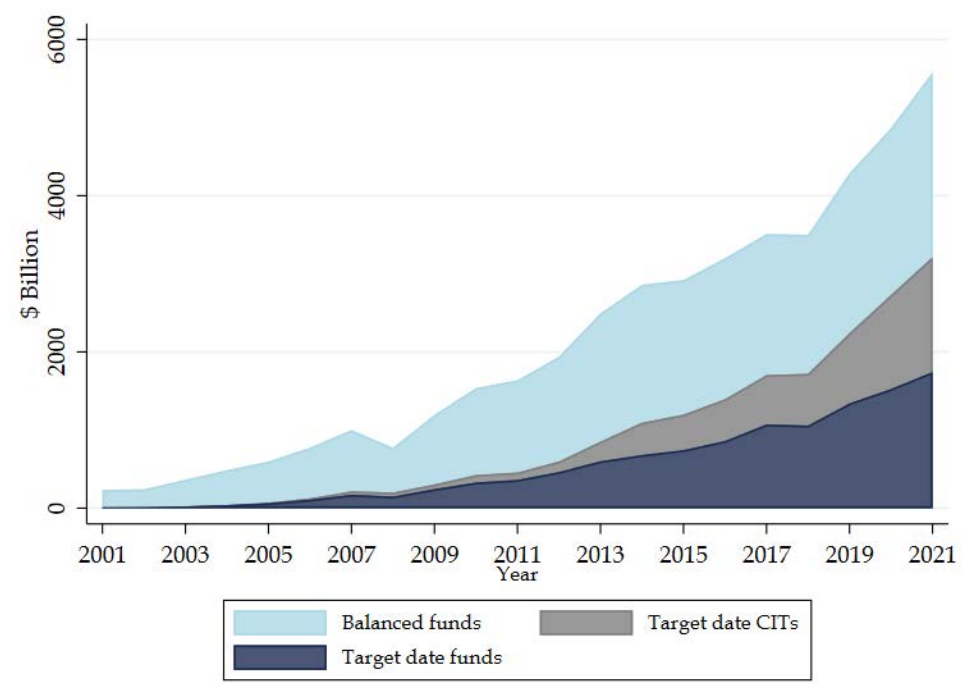


Figure 2: Distribution of index fund share in TDF portfolios

This histogram presents the fractions of TDF portfolios invested in index mutual funds. Observations are for each TDF-quarter and include only TDFs where the value of available holdings (including cash) is larger than $90 \%$ of fund assets.

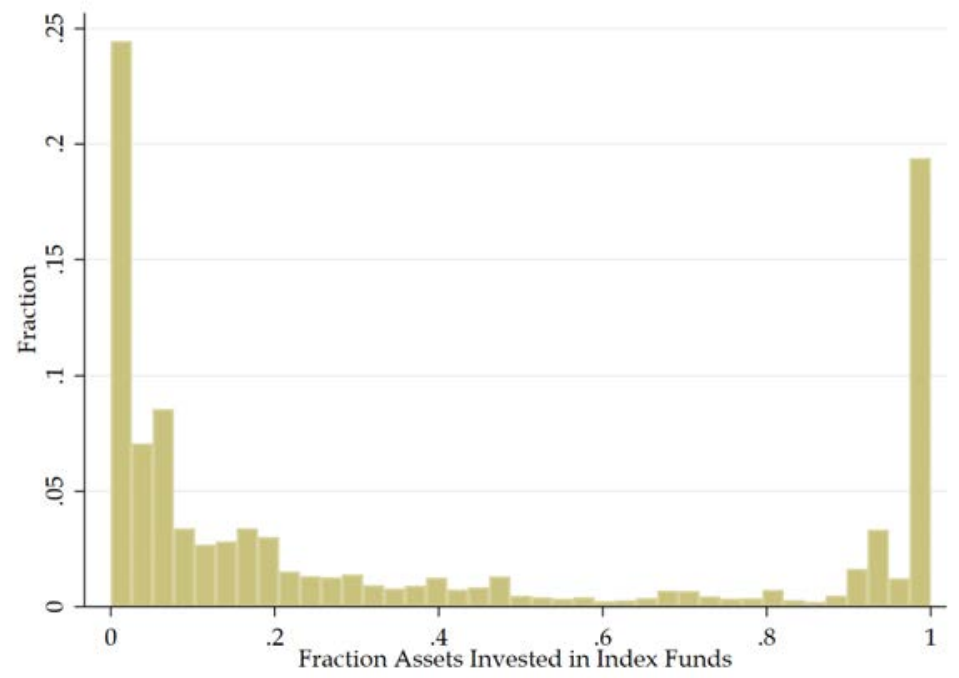


Figure 3: Median rebalancing by equity share

The connected line plots the median ratio of rebalancing for each equity-share-based bin. The outcome variable is calculated as (Rebal. trade $\left.q / T N A_{q-1}\right) /\left(R^{E}-R^{B}\right) \times 0.1$, the amount of rebalancing trade (in equity or bonds) for each dollar of TDF asset divided by $R^{E}-R^{B}$ and multiplied by 0.1 so as to show the amount of rebalancing for each $10 \%$ movement in $R^{E}-R^{B}$. Each bin represents the interval with a length of 0.1 , and the median is taken across time and across TDFs. The bin that centers at 0.25 includes all TDFs whose equity share is at or below $30 \%$ (several bins are combined into one due to small numbers of observations). The dotted line represents the theoretical predicted magnitude of the ratio at the midpoint of each interval. (a) and (b) use the full sample, (c) and (d) use the sample of passive TDFs whose holdings in index mutual funds are at least $50 \%$ of their portfolio values, and (e) and (f) use the sample of active TDFs whose holdings in index funds are less than $50 \%$ of their portfolio values.

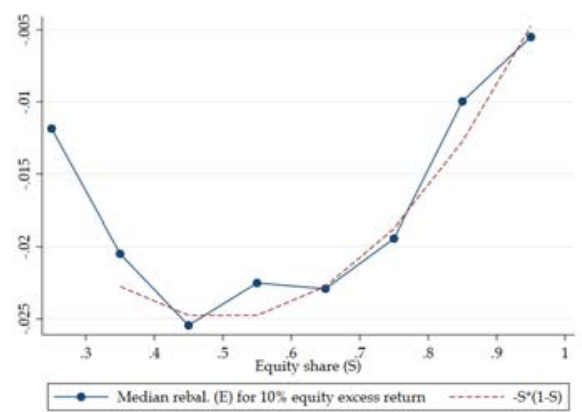

(a) Equity rebalancing - all TDFs

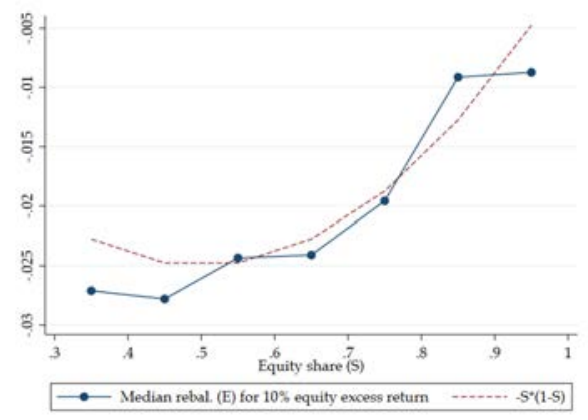

(c) Equity rebalancing - passive TDFs

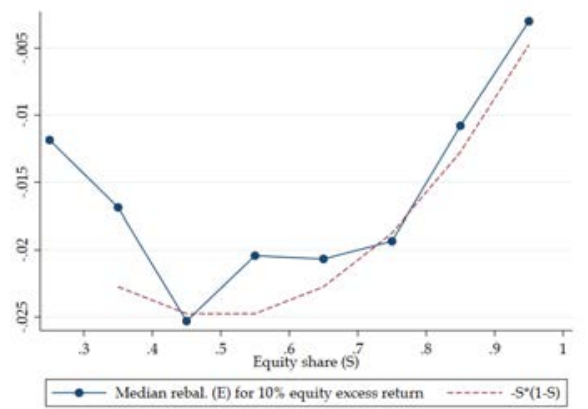

(e) Equity rebalancing - active TDFs

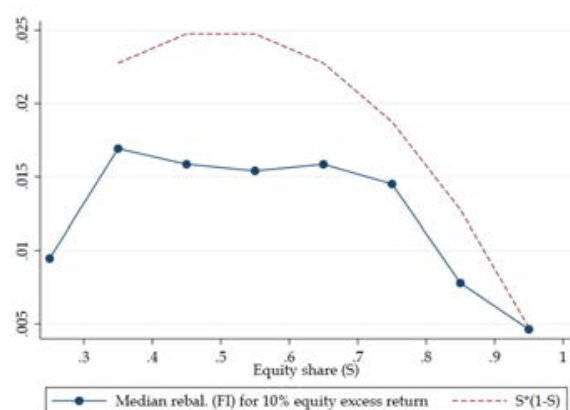

(b) Bond rebalancing - all TDFs

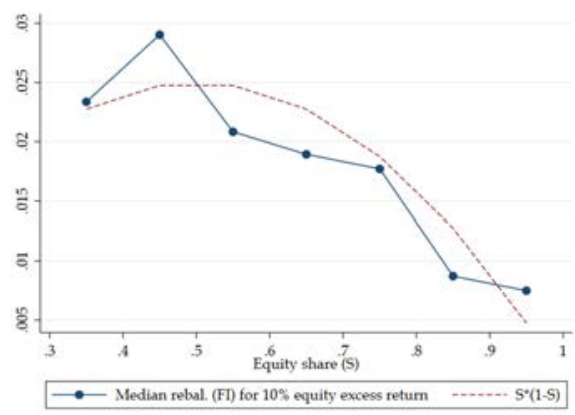

(d) Bond rebalancing - passive TDFs

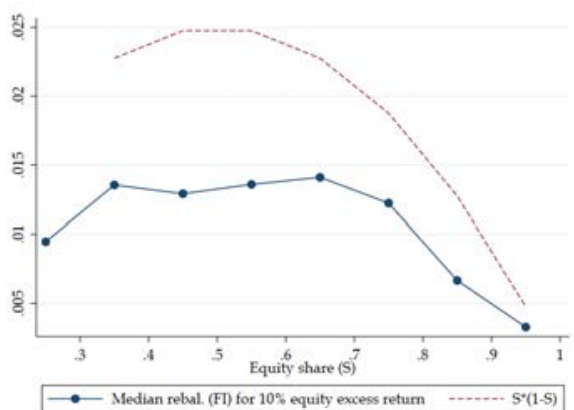

(f) Bond rebalancing - active TDFs 
Figure 4: Aggregate retail/institutional flows and TDF flows to U.S. domestic equity funds

This figure plots the aggregate quarterly dollar flows to U.S. domestic equity mutual funds through retail and institutional share classes (panel A.) and TDF rebalancing (panel B.) during 2008Q3-2018Q4.

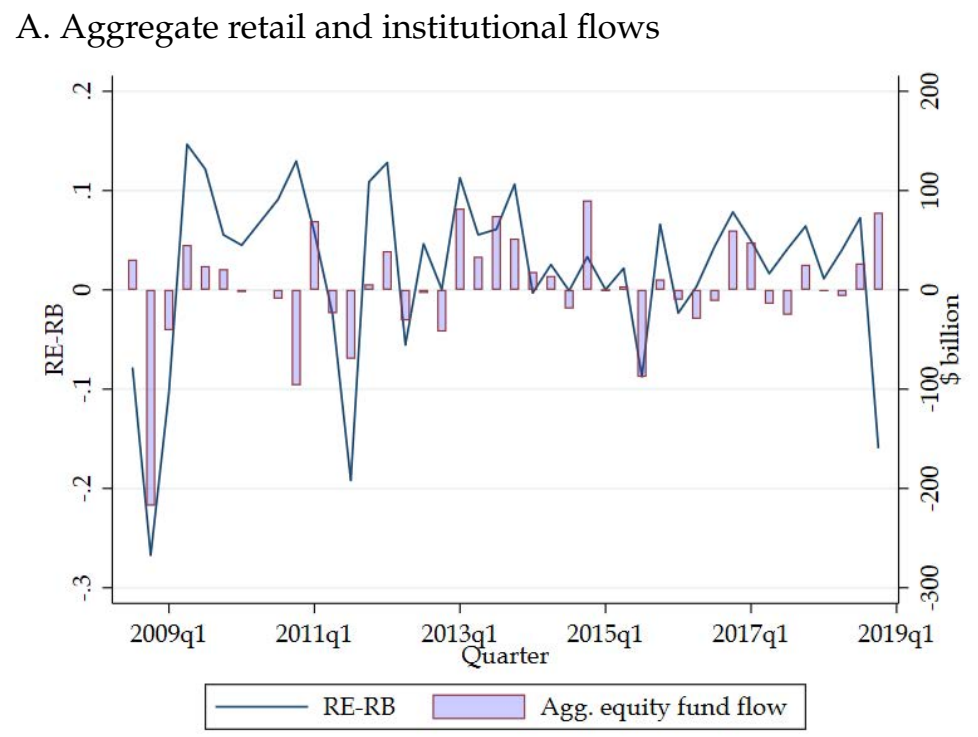

B. Aggregate TDF rebalancing trades

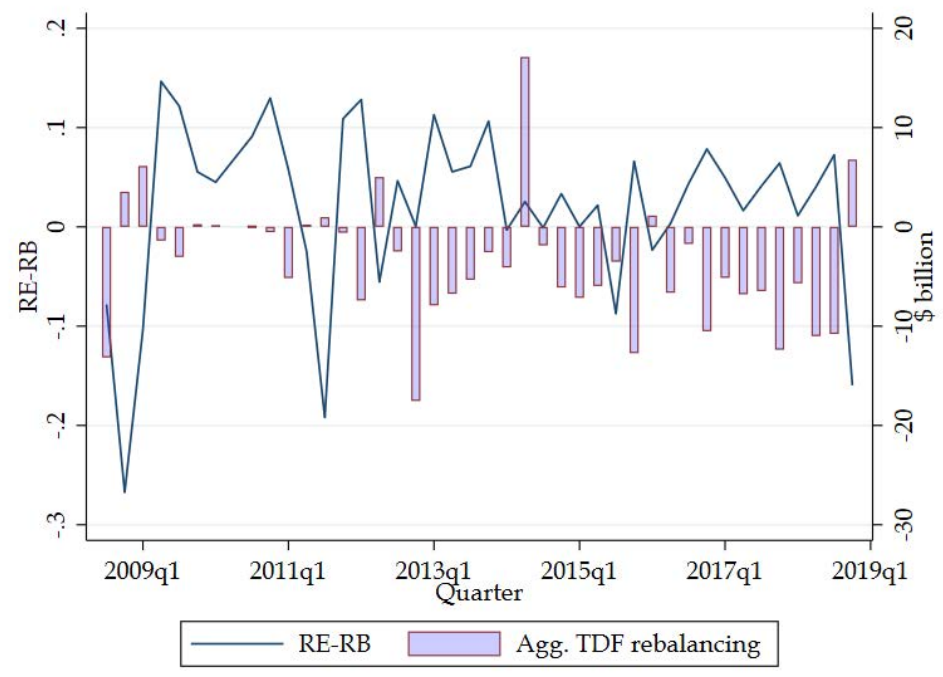


Figure 5: Returns from TDF-based long-short trading strategy

This figure shows the cumulative 7-factor alphas from investing in a portfolio of stocks with the highest TDF ownership and shorting a portfolio with the lowest TDF ownership when the excess stock market return in the current month (panel A) or previous month (panel B) is negative, and the reverse when the excess stock market return is positive. The sample includes NYSE-, NASDAQ-, and AMEX-traded stocks with market capitalizations that are above the fifth percentile on the NYSE and with beginning-of-month prices above five dollars. In each quarter and within each size group based on market capitalization (the size groups are defined according to NYSE size breakpoints that are at 5-percentile increments), stocks are sorted two-ways into quintiles, first by mutual fund ownership (calculated as the sum of ownership by mutual funds which are not held by TDFs), and second by TDF ownership. Cells with fewer than 5 stocks are dropped. The trading strategy in the top panels (bottom panels) invests in the highest TDF portfolio and shorts the lowest TDF portfolio in month $t$ if $\left(R^{E}-R^{B}\right)_{m}<0\left(\left(R^{E}-R^{B}\right)_{m-1}<0\right)$ and takes the reverse positions (long the lowest TDF portfolio and short the highest TDF portfolio) if $\left(R^{E}-R^{B}\right)_{m}>0\left(\left(R^{E}-R^{B}\right)_{m-1}>0\right)$. Betas are estimated using the pre-PPA window of 1996-2005.

\section{A. Current-return strategy (infeasible)}

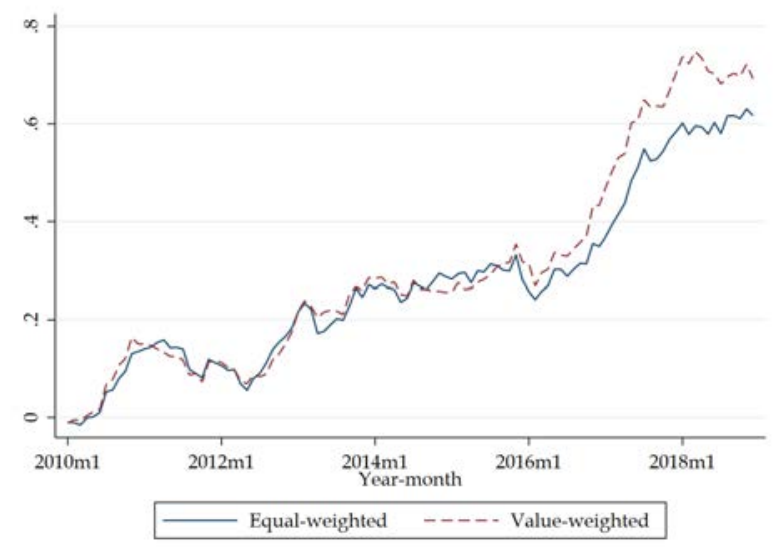

B. Lagged-return strategy

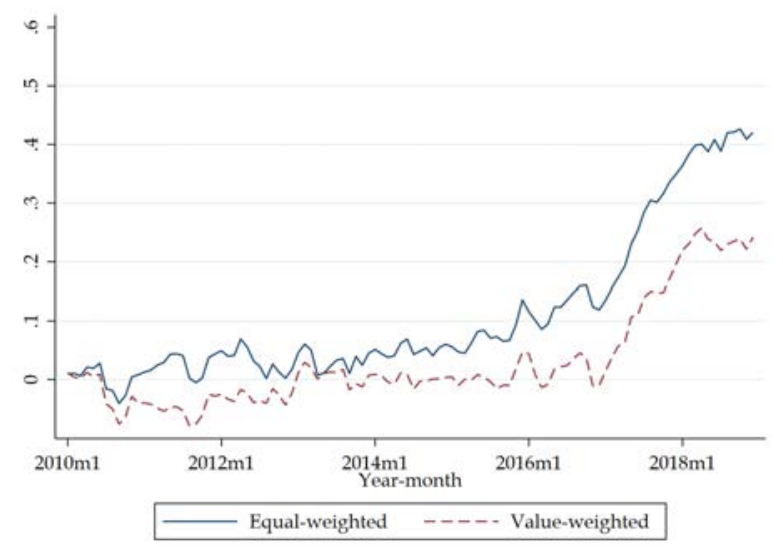


Figure 6: TDF contrarian trades and cumulative stock returns

This figure plots the effect of TDFs on cumulative 7-factor alphas from the month of the return shock (month $m$ ) to month $m+h$. The estimation follows equation (8), and the coefficients $\widehat{\lambda_{h}}$ are plotted as a function of $h$. Betas are calculated using the pre-PPA window 1996-2005. Confidence intervals are based on standard errors that are clustered two ways by stock and time.

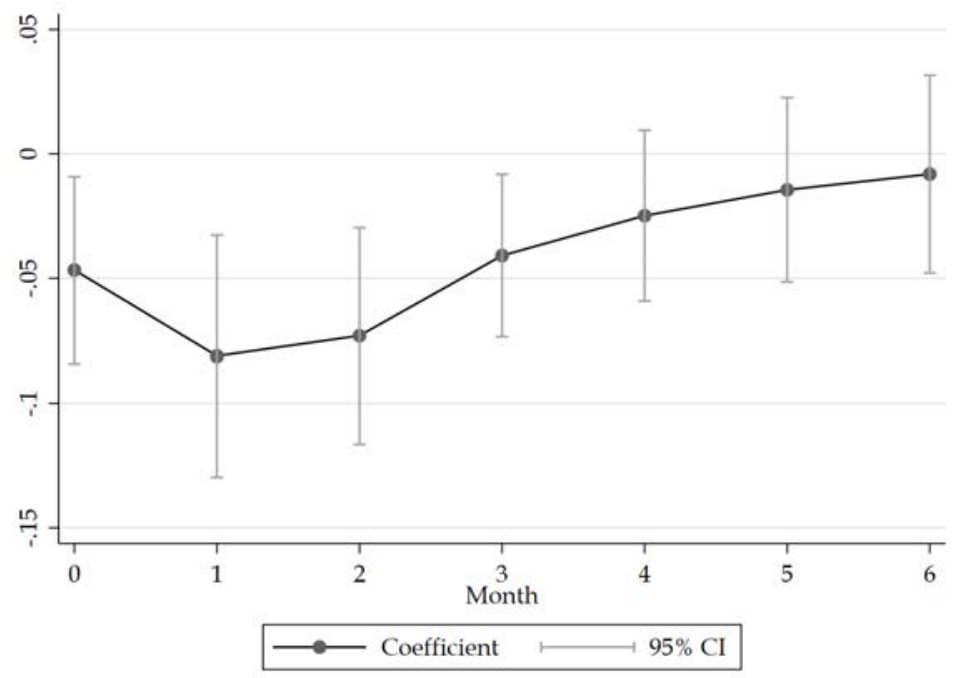


Table 1: Summary statistics on TDFs

This table presents statistics on TDF-quarterly level observations during 2008Q3-2018Q4. TDF holdings are classified into equity and fixed income using the CRSP objective codes of the underlying mutual funds. TDF TNA is the TDF fund size in billion dollars. Target year is the target retirement year stated in the fund name. Years to retirement is Target year minus current calendar year. TDF quarterly return is the net raw return of the TDF in a quarter. Series size is total size across TDFs in a series (a collection of TDFs with the same manager(s) but different target retirement years). Passive TDFs are those with more than $50 \%$ of their assets invested in index funds. No. funds held counts the number of unique mutual funds held by a TDF. Frac. portfolio in mutual funds represents the total values of holdings in mutual funds divided by fund size. Frac. portfolio in equity is the total values of holdings in equity mutual funds divided by fund size, and separately shown for domestic and foreign equity. Cash share is the fraction of fund assets held in cash and obtained from CRSP. Flow to $T D F_{q} / T N A_{q-1}$ is the flow rate to the TDF calculated as the dollar growth in TDF assets in excess of the growth that would have occurred given the net return and the lagged TDF size, divded by lagged size. Total trade in equity (fixed income) $q / T N A_{q-1}$ reflects the dollar amount of total trade in equity (fixed income) that is the sum of trades across all equity (fixed income) mutual funds by the TDF, divided by lagged size. Rebal.trade in equity (fixed income) $q / T N A_{q-1}$ is the total trade less the flow-driven trade which the flow into the TDF allocated to the asset class based on the lagged share in that asset class, divided by lagged size.

\begin{tabular}{|c|c|c|c|c|c|}
\hline TDF quarterly, $N=5,351$ & Mean & p25 & p50 & p75 & SD \\
\hline TDF TNA ( $\$$ billion) & 2.648 & 0.078 & 0.410 & 2.113 & 5.570 \\
\hline Target year & 2032.4 & 2020 & 2030 & 2045 & 14.9 \\
\hline Years to retirement & 17.4 & 6 & 18 & 29 & 14.6 \\
\hline TDF quarterly return (\%) & 1.544 & 0.088 & 2.050 & 4.142 & 4.570 \\
\hline Series size (\$ billion) & 49.181 & 0.893 & 6.258 & 46.529 & 82.207 \\
\hline Passive TDF & 0.325 & 0 & 0 & 1 & 0.468 \\
\hline No. funds held & 15.4 & 8 & 15 & 22 & 8.3 \\
\hline Frac. portfolio in mutual funds (\%) & 95.8 & 93.3 & 97.7 & 99.8 & 5.5 \\
\hline Frac. portfolio in equity (\%) & 73.8 & 59.7 & 78.8 & 89.9 & 18.2 \\
\hline - Domestic equity (\%) & 46.9 & 37.1 & 49.5 & 57.7 & 13.5 \\
\hline - Foreign equity (\%) & 26.9 & 20.8 & 26.9 & 32.4 & 8.9 \\
\hline Cash share $(\%)$ & 3.1 & 0.2 & 1.6 & 4.2 & 5.1 \\
\hline Flow to $T D F_{q} / T N A_{q-1}(\%)$ & 4.679 & -0.940 & 2.792 & 8.148 & 9.714 \\
\hline Total trade in equity $y_{q} / T N A_{q-1}(\%)$ & 3.109 & -1.267 & 1.468 & 5.748 & 7.510 \\
\hline Total trade in fixed income $q$ / TNA $A_{q-1}(\%)$ & 1.282 & -0.118 & 0.791 & 2.220 & 3.289 \\
\hline Rebal. trade in equityq $/ T N A_{q-1}(\%)$ & -0.705 & -1.433 & -0.532 & 0.160 & 2.643 \\
\hline Rebal. trade in fixed income $q$ / TNA $A_{q-1}(\%)$ & 0.438 & -0.150 & 0.306 & 1.012 & 1.909 \\
\hline
\end{tabular}




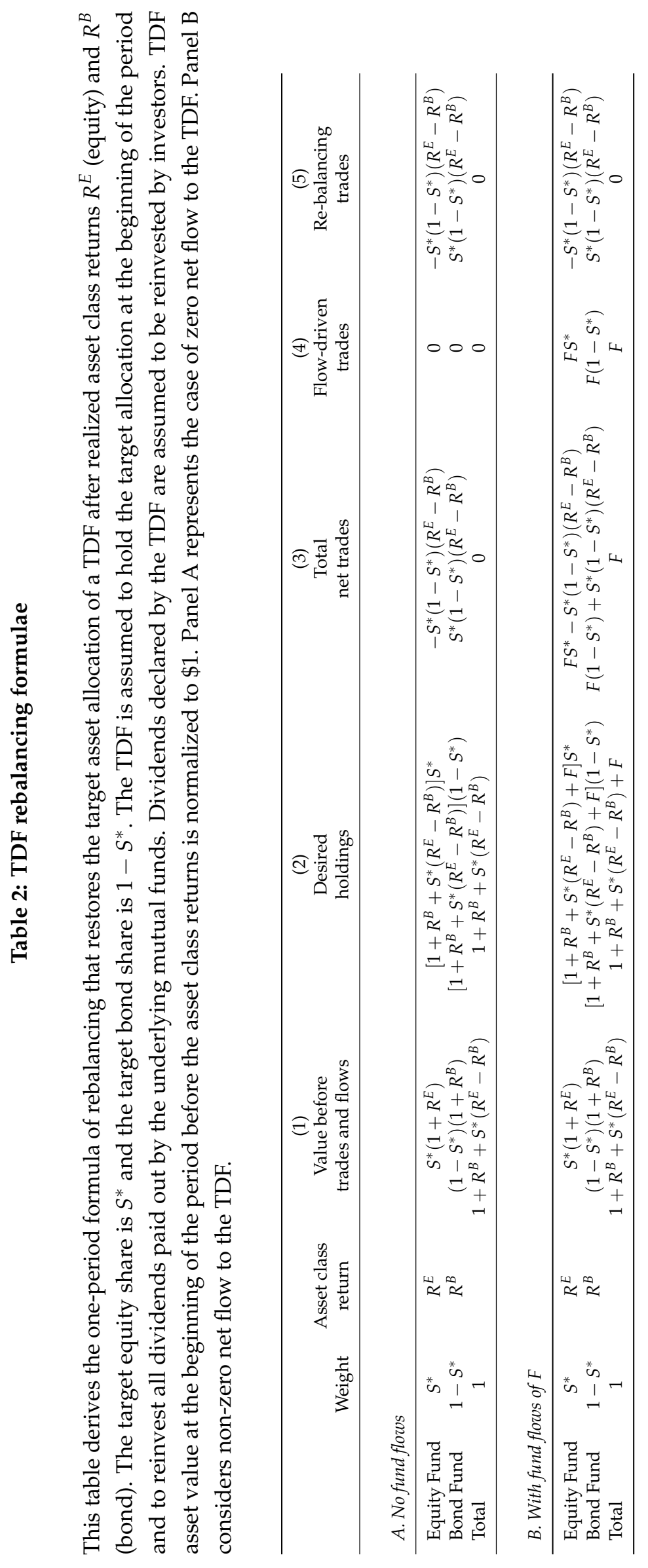


Table 3: TDF rebalancing: actual vs. predicted

This table estimates the relationship between actual rebalancing by TDFs in quarter $q$ and the predicted values of rebalancing given the TDFs' equity shares and realized differential asset-class returns during the third, second, and first months of quarter $q$ and during $q-1 . \operatorname{Rebal}(E)_{q} / T N A_{q-1}\left(\operatorname{Rebal}(F I)_{q} / T N A_{q-1}\right)$ in panel A (B) is TDF-level rebalancing trade in quarter $q$ with respect with equity (bond), divided by TDF TNA in quarter $q-1$ and winsorized at $1 \%$ and $99 \%$. Pred.rebal $q_{q, m=t}$ stands for predicted rebalancing in response to the realized return of the $t$ th month of quarter $q$, and is calculated as $-S(1-S)\left(R^{E}-R^{B}\right)_{q, m=t}$ in panel A and $S(1-S)\left(R^{E}-R^{B}\right)_{q, m=t}$ in panel $\mathrm{B}$, where $S$ is the TDF's equity share in $q-1$ and $\left(R^{E}-R^{B}\right)_{q, m=t}$ stands for the monthly excess return of the equity market over the bond market in month $t$. Pred.rebal $q_{-1}$ stands for the value of predicted rebalancing in response to the realized return of quarter $q-1$. $R^{E}$ is approximated by the weighted average between total U.S. and foreign equity market return in columns 1-4, where the weights follow the proportions of domestic and foreign equity in a TDF's equity holdings in quarter $q-1$, and by the U.S. only equity market return in columns 5-8. The sample is restricted to TDF-quarters during 2008Q3-2018Q4 where the value of available holdings (including cash) is larger than $90 \%$ of fund assets, the equity share does not change by more than $5 \%$ from the previous quarter (to exclude glide path adjustments), and the fund assets do not grow by more than $50 \%$ from the previous quarter (to exclude fund mergers). Control variables include lagged quarter's log TDF TNA, log Series size, Cash share, and current quarter's TDF flow rate, TDF quarterly return, and Years to retirement. Standard errors are clustered two ways by TDF and quarter. ${ }^{*} \mathrm{p}<.1$; ${ }^{* *} \mathrm{p}<.05 ;{ }^{* * *} \mathrm{p}<.01$.

\begin{tabular}{|c|c|c|c|c|c|c|c|c|}
\hline & (1) & (2) & (3) & (4) & (5) & (6) & (7) & (8) \\
\hline \multirow[t]{3}{*}{ A. } & \multicolumn{8}{|c|}{$\operatorname{Rebal}(E)_{q} / T N A_{q-1}$} \\
\hline & \multicolumn{4}{|c|}{ US+Foreign $R^{E}$} & \multicolumn{4}{|c|}{ US $R^{E}$} \\
\hline & \multicolumn{2}{|c|}{ All } & Passive & Active & \multicolumn{2}{|c|}{ All } & Passive & Active \\
\hline \multirow{2}{*}{ Pred.rebal $l_{q, m=3}$} & $0.442^{* *}$ & $0.436^{* *}$ & $0.503^{* * *}$ & 0.408 & $0.487^{* *}$ & $0.403^{* *}$ & $0.457^{* * *}$ & 0.393 \\
\hline & $(0.215)$ & $(0.193)$ & $(0.116)$ & $(0.260)$ & $(0.207)$ & $(0.191)$ & $(0.120)$ & $(0.248)$ \\
\hline \multirow{2}{*}{ Pred.rebal $l_{q, m=2}$} & $0.695^{* * *}$ & $0.727^{* * *}$ & $0.762^{* * *}$ & $0.710^{* *}$ & $0.588^{* * *}$ & $0.567^{* * *}$ & $0.689^{* * *}$ & $0.504^{* *}$ \\
\hline & $(0.185)$ & $(0.200)$ & $(0.114)$ & $(0.270)$ & $(0.202)$ & $(0.191)$ & $(0.126)$ & $(0.240)$ \\
\hline \multirow{2}{*}{ Pred.rebal $l_{q, m=1}$} & $0.829^{* * *}$ & $0.831^{* * *}$ & $0.852^{* * *}$ & $0.818^{* * *}$ & $0.746^{* * *}$ & $0.706^{* * *}$ & $0.789^{* * *}$ & $0.655^{* * *}$ \\
\hline & $(0.139)$ & $(0.128)$ & $(0.092)$ & $(0.166)$ & (0.159) & $(0.148)$ & $(0.097)$ & $(0.198)$ \\
\hline \multirow[t]{2}{*}{ Pred.rebal $_{q-1}$} & $0.213^{*}$ & $0.218^{*}$ & 0.116 & $0.272^{*}$ & $0.195^{*}$ & $0.206^{*}$ & $0.140^{*}$ & 0.234 \\
\hline & $(0.111)$ & $(0.117)$ & $(0.070)$ & $(0.151)$ & $(0.112)$ & $(0.116)$ & $(0.073)$ & $(0.144)$ \\
\hline Controls & no & yes & yes & yes & no & yes & yes & yes \\
\hline TDF FE & yes & yes & yes & yes & yes & yes & yes & yes \\
\hline Observations & 4,670 & 4,670 & 1,539 & 3,131 & 4,670 & 4,670 & 1,539 & 3,131 \\
\hline R-squared & 0.228 & 0.235 & 0.434 & 0.214 & 0.220 & 0.228 & 0.427 & 0.206 \\
\hline \multirow[t]{3}{*}{$B$. } & \multicolumn{8}{|c|}{$\operatorname{Rebal}(F I)_{q} / T N A_{q-1}$} \\
\hline & \multicolumn{4}{|c|}{ US+Foreign $R^{E}$} & \multicolumn{4}{|c|}{ US $R^{E}$} \\
\hline & \multicolumn{2}{|c|}{ All } & Passive & Active & \multicolumn{2}{|c|}{ All } & Passive & Active \\
\hline \multirow[t]{2}{*}{ Pred.rebal ${ }_{q, m=3}$} & 0.179 & 0.087 & -0.081 & $0.284^{* *}$ & 0.207 & 0.086 & -0.118 & $0.288^{* *}$ \\
\hline & $(0.151)$ & $(0.220)$ & $(0.335)$ & $(0.126)$ & $(0.129)$ & $(0.201)$ & $(0.299)$ & $(0.115)$ \\
\hline \multirow[t]{2}{*}{ Pred.rebal,$m=2$} & $0.778^{* * *}$ & $0.660^{* * *}$ & $1.085^{* * *}$ & $0.398^{* * *}$ & $0.723^{* * *}$ & $0.594^{* * *}$ & $0.996^{* * *}$ & $0.358^{* *}$ \\
\hline & $(0.169)$ & $(0.144)$ & $(0.210)$ & $(0.136)$ & $(0.168)$ & $(0.143)$ & $(0.197)$ & $(0.134)$ \\
\hline \multirow[t]{2}{*}{ Pred.rebal ${ }_{q, m=1}$} & $0.694^{* * *}$ & $0.597^{* * *}$ & $0.883^{* * *}$ & $0.390^{* * *}$ & $0.651^{* * *}$ & $0.534^{* * *}$ & $0.821^{* * *}$ & $0.331^{* * *}$ \\
\hline & $(0.160)$ & $(0.143)$ & $(0.159)$ & $(0.120)$ & $(0.154)$ & $(0.135)$ & $(0.157)$ & $(0.111)$ \\
\hline \multirow{2}{*}{ Pred.rebal $_{q-1}$} & $0.190^{*}$ & 0.183 & $0.383^{* *}$ & 0.013 & 0.183 & 0.175 & $0.380^{* *}$ & 0.013 \\
\hline & (0.112) & (0.121) & $(0.188)$ & $(0.070)$ & (0.112) & $(0.115)$ & (0.177) & (0.073) \\
\hline Controls & no & yes & yes & yes & no & yes & yes & yes \\
\hline TDF FE & yes & yes & yes & yes & yes & yes & yes & yes \\
\hline Observations & 4,670 & 4,670 & 1,539 & 3,131 & 4,670 & 4,670 & 1,539 & 3,131 \\
\hline R-squared & 0.260 & 0.266 & 0.439 & 0.221 & 0.254 & 0.262 & 0.433 & 0.221 \\
\hline
\end{tabular}




\section{Table 4: Effect of TDF ownership on mutual fund flows}

This table estimates the effect of TDF ownership on the mutual fund flow-performance relationship during 2008.7-2018.12. Observations are at the mutual fund monthly level. The sample in columns 1-3 (4-6) includes retail and institutional domestic equity funds (corporate bond funds) which are held by any TDF during the sample period. The dependent variable Fund flow is the monthly fund flow rate, defined as the growth rate in fund assets in excess of the realized net fund return. Observations where the lagged asset size is less than $\$ 10$ million or where the dependent variable is below $1 \%$ or above $99 \%$ are dropped. $R^{E}-R^{B}$ is the excess return of the U.S. total stock market over the U.S. total bond market. Frac.by TDFs is measured as the fraction of fund assets held by TDFs, measured at the end of the previous quarter. Index fund equals one if a mutual fund is an index fund. Control variables include the lagged month's log Fund size, log Fund family size, current month's log Fund age, Expense ratio, and lagged Return volatility. Standard errors are clustered two ways by time and fund. ${ }^{*} \mathrm{p}<.1 ;{ }^{* *} \mathrm{p}<.05 ;{ }^{* * *} \mathrm{p}<.01$.

\begin{tabular}{|c|c|c|c|c|c|c|}
\hline & (1) & (2) & (3) & (4) & (5) & (6) \\
\hline & \multicolumn{6}{|c|}{ Fund flowt } \\
\hline & \multicolumn{3}{|c|}{ Domestic equity funds } & \multicolumn{3}{|c|}{ Corporate bond funds } \\
\hline & All & Index & Active & All & Index & Active \\
\hline$\left(R^{E}-R^{B}\right)_{t} \times$ Frac.by TDFs $s_{q-1}$ & $\begin{array}{c}-0.093^{* * *} \\
(0.030)\end{array}$ & $\begin{array}{c}-0.251^{* *} \\
(0.102)\end{array}$ & $\begin{array}{c}-0.075^{* *} \\
(0.033)\end{array}$ & $\begin{array}{l}0.121^{*} \\
(0.072)\end{array}$ & $\begin{array}{c}0.178 \\
(0.163)\end{array}$ & $\begin{array}{c}0.109 \\
(0.084)\end{array}$ \\
\hline$\left(R^{E}-R^{B}\right)_{t-1} \times$ Frac.by TDFs $s_{q-1}$ & $\begin{array}{c}-0.112^{* * *} \\
(0.029)\end{array}$ & $\begin{array}{c}-0.185^{* * *} \\
(0.068)\end{array}$ & $\begin{array}{c}-0.106^{* * *} \\
(0.031)\end{array}$ & $\begin{array}{l}0.206^{* * *} \\
(0.067)\end{array}$ & $\begin{array}{c}0.542^{* * *} \\
(0.128)\end{array}$ & $\begin{array}{l}0.156^{* *} \\
(0.070)\end{array}$ \\
\hline$\left(R^{E}-R^{B}\right)_{t}$ & $\begin{array}{l}0.035^{* *} \\
(0.016)\end{array}$ & $\begin{array}{c}0.086^{* * *} \\
(0.022)\end{array}$ & $\begin{array}{l}0.034^{* *} \\
(0.015)\end{array}$ & $\begin{array}{c}0.088^{* * *} \\
(0.020)\end{array}$ & $\begin{array}{l}0.100^{* *} \\
(0.045)\end{array}$ & $\begin{array}{c}0.088^{* * *} \\
(0.020)\end{array}$ \\
\hline$\left(R^{E}-R^{B}\right)_{t} \times$ Index fund & $\begin{array}{c}0.042 \\
(0.028)\end{array}$ & & & $\begin{array}{c}0.012 \\
(0.040)\end{array}$ & & \\
\hline$\left(R^{E}-R^{B}\right)_{t-1}$ & $\begin{array}{c}0.011 \\
(0.013)\end{array}$ & $\begin{array}{c}0.058^{* * *} \\
(0.019)\end{array}$ & $\begin{array}{c}0.010 \\
(0.013)\end{array}$ & $\begin{array}{l}0.040^{* *} \\
(0.017)\end{array}$ & $\begin{array}{l}-0.059 \\
(0.042)\end{array}$ & $\begin{array}{l}0.043^{* *} \\
(0.017)\end{array}$ \\
\hline$\left(R^{E}-R^{B}\right)_{t-1} \times$ Index fund & $\begin{array}{l}0.041^{* *} \\
(0.021)\end{array}$ & & & $\begin{array}{c}-0.081^{* *} \\
(0.039)\end{array}$ & & \\
\hline Frac.by TDFs $s_{q-1}$ & $\begin{array}{l}0.006^{* *} \\
(0.002)\end{array}$ & $\begin{array}{c}0.007 \\
(0.007)\end{array}$ & $\begin{array}{l}0.005^{* *} \\
(0.003)\end{array}$ & $\begin{array}{c}0.000 \\
(0.006)\end{array}$ & $\begin{array}{c}0.001 \\
(0.012)\end{array}$ & $\begin{array}{l}-0.000 \\
(0.007)\end{array}$ \\
\hline Controls & yes & yes & yes & yes & yes & yes \\
\hline Fund FE & yes & yes & yes & yes & yes & yes \\
\hline Time FE & no & no & no & no & no & no \\
\hline Observations & 32,816 & 6,727 & 26,089 & 10,151 & 2,280 & 7,871 \\
\hline R-squared & 0.171 & 0.115 & 0.183 & 0.226 & 0.204 & 0.224 \\
\hline
\end{tabular}


Table 5: Aggregate retail and institutional vs. TDF flows to U.S. equity funds

This table estimates the flow sensitivity to the excess performance of the equity market for i) retail and institutional U.S. equity funds, ii) TDF rebalancing trades, and iii) TDF total trades. The dependent variable in column 1, Retail and inst. flow $w_{q}$, is calculated as the aggregate dollar flows to retail and institutional share classes of domestic equity funds in quarter $q$ divided by the total assets under management in those share classes in quarter $q-1$. TDF trades are deducted before aggregating up the retail and institutional flows. The dependent variable in column 2 (column 3), TDF rebal. trades $q$ (TDF total trades $s_{q}$ ), is the aggregate dollar rebalancing (total) trade by TDFs in quarter $q$ divided by the total size of TDFs in quarter $q-1 . R^{E}-R^{B}$ is the excess return of the U.S. total stock market over the U.S. total bond market. The sample period is 2008Q3-2018Q4. 2010Q2 is dropped due to insufficient TDF trading data. Robust standard errors are reported. ${ }^{*} \mathrm{p}<.1 ;{ }^{* *} \mathrm{p}<.05 ;{ }^{* * *} \mathrm{p}<.01$.

\begin{tabular}{lccc}
\hline & $(1)$ & $(2)$ & $(3)$ \\
\hline & $\begin{array}{c}\text { Retail and inst. } \text { flow }_{q} \\
\left(R^{E}-R^{B}\right)_{q}\end{array}$ & $\begin{array}{c}\text { TDF rebal. } \\
\text { trades }_{q}\end{array}$ & $\begin{array}{c}\text { TDF total } \\
\text { trades }_{q}\end{array}$ \\
$\left(R^{E}-R^{B}\right)_{q-1}$ & $0.087^{* *}$ & $-0.095^{* *}$ & -0.034 \\
& $0.037)$ & $(0.039)$ & $(0.038)$ \\
Constant & $(0.013)$ & $-0.100^{*}$ & $-0.128^{*}$ \\
& -0.003 & -0.004 & $(0.068)$ \\
& $(0.002)$ & $(0.004)$ & $\left(0.0051^{* *}\right.$ \\
\hline Observations & 41 & 41 & 41 \\
R-squared & 0.432 & 0.271 & 0.208 \\
\hline
\end{tabular}


Table 6: Summary statistics: stocks with high- and low TDF ownership

This table presents summary statistics of stocks with high and low indirect TDF ownership. The sample includes NYSE-, NASDAQ-, and AMEX-traded stocks with market capitalizations that are above the fifth percentile on the NYSE and with beginning-of-month prices above five dollars during 2010-2018. High (low) TDF indicates if a stock has above (below) median TDF ownership in each month, where TDF ownership is calculated at the end of the previous quarter. Stock betas are estimated using a 7-factor model that includes Market-rf, SMB, HML (Fama and French, 1993), momentum (Carhart, 1997), liquidity (Pástor and Stambaugh, 2003), profitability, and investment (Fama and French, 2015). Beta loadings are estimated using both the pre-PPA window of 1996-2005 and 36-month rolling windows. TDF ownership refers to the fraction of a stock owned indirectly by TDFs through mutual funds. Mutual fund ownership is the fraction of a stock owned by equity mutual funds that have no investment from TDFs. Market capitalization is measured in billion dollars, trading volume is normalized by the number of shares outstanding, market-to-book is the ratio between market value and book value of common shares, dividend yield $12 \mathrm{~m}$ is the trailing-12-month cash dividend per share divided by the share price, ROE is calculated as quarterly (revenue-COGS-SG\&A-interest expense) divided by lagged book value of common shares, and investment measures the quarterly growth rate in total assets. Illiquidity is the quarterly average of the Amihud (2002) daily illiquidity measure. Income statement and balance sheet data are from COMPUSTAT. p-values of difference tests on means are reported.

\begin{tabular}{|c|c|c|c|c|c|}
\hline \multirow[t]{2}{*}{ Stock monthly } & \multicolumn{2}{|c|}{$\begin{array}{l}\text { High TDF } \\
N=73,226\end{array}$} & \multicolumn{2}{|c|}{$\begin{array}{l}\text { Low TDF } \\
\mathrm{N}=62,489\end{array}$} & \multirow[b]{2}{*}{ p-value } \\
\hline & Mean & SD & Mean & SD & \\
\hline Monthly return $_{m}(\%)$ & 1.148 & 8.977 & 1.403 & 9.784 & 0.00 \\
\hline 7-Factor market beta pre-window & 1.084 & 0.596 & 0.936 & 0.642 & 0.00 \\
\hline 7-Factor market beta rolling ${ }_{m-1}$ & 1.043 & 0.574 & 0.973 & 0.653 & 0.00 \\
\hline 7-Factor alpha pre-window $w_{m}(\%)$ & 0.112 & 8.438 & 0.557 & 9.206 & 0.00 \\
\hline 7-Factor alpha rolling-window $w_{m}(\%)$ & 0.148 & 8.503 & 0.521 & 9.564 & 0.00 \\
\hline TDF ownership $q-1(\%)$ & 0.873 & 0.763 & 0.318 & 0.223 & 0.00 \\
\hline Market capitalization $_{m-1}$ (\$ billion) & 15.937 & 45.229 & 5.301 & 20.156 & 0.00 \\
\hline Mutual fund ownership $p_{-1}(\%)$ & 27.691 & 9.027 & 22.404 & 10.866 & 0.00 \\
\hline (Monthly volume/Shares out. $)_{m-1}$ & 0.198 & 0.162 & 0.156 & 0.177 & 0.00 \\
\hline Market-to-book ratio ${ }_{q-1}$ & 3.659 & 5.118 & 3.155 & 4.660 & 0.00 \\
\hline Dividend yield $12 m_{q-1}(\%)$ & 1.672 & 6.481 & 1.886 & 6.805 & 0.00 \\
\hline$R O E_{q-1}(\%)$ & 6.964 & 10.398 & 4.953 & 10.603 & 0.00 \\
\hline Investment $_{q-1}(\%)$ & 2.397 & 10.132 & 2.309 & 10.532 & 0.11 \\
\hline Illiquidity $_{q-1}$ & 0.030 & 0.032 & 0.074 & 0.100 & 0.00 \\
\hline $\operatorname{Return}_{m-1}(\%)$ & 1.332 & 8.915 & 1.638 & 10.103 & 0.00 \\
\hline Return $_{m-6 \text { to } m-2}(\%)$ & 7.506 & 18.835 & 7.598 & 21.585 & 0.40 \\
\hline
\end{tabular}


Table 7: TDF ownership and stock return sensitivity to market performance

This table examines the relationship between TDF ownership and monthly stock return sensitivity to differential asset class performance during 2010-2018. The dependent variable 7-factor alpha is the riskadjusted return winsorized at $1 \%$ and $99 \%$, where the factors include Market-rf, SMB, HML (Fama and French, 1993), momentum (Carhart, 1997), liquidity (Pástor and Stambaugh, 2003), profitability, and investment (Fama and French, 2015). Beta loadings are estimated using 1996-2005 (36-month rolling windows) in panel A (panel B). TDF (\%) is the percentage of a stock indirectly owned by TDFs measured at the end of the previous quarter. Return $n_{m-1}$ and Return $n_{m-6}$ to $m-2$ are raw returns in month $m-1$ and cumulative raw returns during months $m-6$ to $m-2$, respectively. The pre-PPA period (falsification test) includes 1987-2005 and factor betas for that test use the window 1977-1986 in panel A and 36-month rolling windows in panel B. TDF(\%) in the falsification test is measured as averages during 2010-2018. The sample includes NYSE-, NASDAQ-, and AMEX-traded stocks with market capitalizations that are above the fifth percentile on the NYSE and with beginning-of-month prices above five dollars. Control variables include log of lagged values of Market capitalization, Monthly volume/Shares out., Market-to-book ratio, and lagged values of Dividend yield 12m, ROE, Investment, Illiquidity, and Mutual fund ownership. Standard errors in this table are clustered two ways by time and stock.

\begin{tabular}{|c|c|c|c|c|c|}
\hline & (1) & (2) & (3) & (4) & (5) \\
\hline A. & \multicolumn{4}{|c|}{$\begin{array}{l}\text { 2010-2018 } \\
\text { 7-Factor alpha pre-window }\end{array}$} & Pre-PPA \\
\hline$\left(R^{E}-R^{B}\right)_{m} \times T D F_{q-1}(\%)$ & $\begin{array}{c}-0.039 * * \\
(0.020)\end{array}$ & $\begin{array}{c}-0.047^{* *} \\
(0.020)\end{array}$ & $\begin{array}{c}-0.049^{* *} \\
(0.019)\end{array}$ & $\begin{array}{c}-0.050^{* *} \\
(0.019)\end{array}$ & $\begin{array}{c}0.062 \\
(0.054)\end{array}$ \\
\hline$\left(R^{E}-R^{B}\right)_{m-1} \times T D F_{q-1}(\%)$ & $\begin{array}{l}-0.001 \\
(0.014)\end{array}$ & $\begin{array}{l}-0.005 \\
(0.014)\end{array}$ & $\begin{array}{l}-0.012 \\
(0.015)\end{array}$ & $\begin{array}{c}-0.024 \\
(0.016)\end{array}$ & $\begin{array}{l}-0.012 \\
(0.028)\end{array}$ \\
\hline$T D F_{q-1}(\%)$ & $\begin{array}{l}-0.002^{* * *} \\
(0.001)\end{array}$ & $\begin{array}{l}-0.001 \\
(0.001)\end{array}$ & $\begin{array}{l}-0.001 \\
(0.001)\end{array}$ & $\begin{array}{l}-0.001 \\
(0.001)\end{array}$ & $\begin{array}{c}0.000 \\
(0.001)\end{array}$ \\
\hline Return $_{m-1}$ & & & $\begin{array}{c}-0.027^{* * *} \\
(0.008)\end{array}$ & $\begin{array}{l}-0.028^{* * *} \\
(0.007)\end{array}$ & $\begin{array}{l}-0.059^{* * *} \\
(0.008)\end{array}$ \\
\hline Return $_{m-6 \text { to } m-2}$ & & & $\begin{array}{c}-0.004 \\
(0.004)\end{array}$ & $\begin{array}{c}-0.005 \\
(0.004)\end{array}$ & $\begin{array}{c}0.007 \\
(0.004)\end{array}$ \\
\hline Controls & no & yes & yes & yes & yes \\
\hline Characteristics $\times\left(R^{E}-R^{B}\right)$ & no & no & no & yes & yes \\
\hline Time-by-industry FE & yes & yes & yes & yes & yes \\
\hline Observations & 148,583 & 131,443 & 127,341 & 127,341 & 118,205 \\
\hline R-squared & 0.218 & 0.229 & 0.230 & 0.231 & 0.325 \\
\hline$B$. & \multicolumn{5}{|c|}{ 7-Factor alpha rolling-window $w_{m}$} \\
\hline$\left(R^{E}-R^{B}\right)_{m} \times T D F_{q-1}(\%)$ & $\begin{array}{l}-0.020^{*} \\
(0.011)\end{array}$ & $\begin{array}{l}-0.020^{*} \\
(0.010)\end{array}$ & $\begin{array}{l}-0.019^{*} \\
(0.011)\end{array}$ & $\begin{array}{l}-0.026^{* *} \\
(0.011)\end{array}$ & $\begin{array}{c}0.003 \\
(0.016)\end{array}$ \\
\hline$\left(R^{E}-R^{B}\right)_{m-1} \times T D F_{q-1}(\%)$ & $\begin{array}{l}-0.008 \\
(0.012)\end{array}$ & $\begin{array}{l}-0.010 \\
(0.011)\end{array}$ & $\begin{array}{l}-0.013 \\
(0.012)\end{array}$ & $\begin{array}{l}-0.017 \\
(0.011)\end{array}$ & $\begin{array}{l}-0.021 \\
(0.020)\end{array}$ \\
\hline$T D F_{q-1}(\%)$ & $\begin{array}{l}-0.002^{* * *} \\
(0.000)\end{array}$ & $\begin{array}{l}-0.001^{* *} \\
(0.000)\end{array}$ & $\begin{array}{c}-0.001^{* * *} \\
(0.000)\end{array}$ & $\begin{array}{c}-0.001^{* *} \\
(0.000)\end{array}$ & $\begin{array}{c}0.002^{* * *} \\
(0.001)\end{array}$ \\
\hline Return $_{m-1}$ & & & $\begin{array}{l}-0.012 \\
(0.010)\end{array}$ & $\begin{array}{l}-0.013 \\
(0.010)\end{array}$ & $\begin{array}{c}-0.061^{* * *} \\
(0.019)\end{array}$ \\
\hline Return $_{m-6 \text { to } m-2}$ & & & $\begin{array}{l}-0.004 \\
(0.004)\end{array}$ & $\begin{array}{l}-0.004 \\
(0.005)\end{array}$ & $\begin{array}{l}-0.002 \\
(0.007)\end{array}$ \\
\hline Controls & no & yes & yes & yes & yes \\
\hline Characteristics $\times\left(R^{E}-R^{B}\right)$ & no & no & no & yes & yes \\
\hline Time-by-industry FE & yes & yes & yes & yes & yes \\
\hline Observations & 205,786 & 181,642 & 176,576 & 176,576 & 229,006 \\
\hline R-squared & 0.166 & 0.172 & 0.172 & 0.172 & 0.208 \\
\hline
\end{tabular}


Table 8: Relationship between S\&P 500 index inclusion and TDF investment

This table estimates the effect of S\&P 500 index inclusion on stock-level TDF ownership. Observations are at stock-by-quarter level during 2010-2018, and the sample contains S\&P 500 stocks and control stocks matched on industry, size, and liquidity, following Denis et al. (2003). The dependent variable in column 1 is the indirect ownership by all TDFs through mutual funds, in column 2 the indirect ownership by all TDFs through index funds, in column 3 the indirect ownership by all TDFs through actively managed funds, in column 4 the indirect ownership by passive TDFs through index funds, and in column 5 the indirect ownership by active TDFs through index funds. $S \& P 500_{q}$ is an indicator that equals one if the stock is included in the S\&P 500 index quarter $q$ and zero otherwise. Control variables include log of lagged values of Market capitalization, Monthly volume/Shares out., Market-to-book ratio, and lagged values of Dividend yield $12 \mathrm{~m}, \mathrm{ROE}$, Investment, Illiquidity, Mutual fund ownership and the quarterly return of the stock. Standard errors are clustered by stock.

\begin{tabular}{lccccc}
\hline & $(1)$ & $(2)$ & $(3)$ & $(4)$ & $(5)$ \\
\hline & & & Indirect & TDF ownership $q$ (\%) \\
& & & Passive TDF \\
& TDF total & TDF $\rightarrow$ index & TDF $\rightarrow$ active & $\rightarrow$ index & $\rightarrow$ active \\
\hline S\&P 500 $q$ & $0.208^{* *}$ & $0.091^{* * *}$ & 0.118 & $0.020^{*}$ & $0.070^{* * *}$ \\
& $(0.082)$ & $(0.012)$ & $(0.079)$ & $(0.010)$ & $(0.004)$ \\
\hline Controls & yes & yes & yes & yes & yes \\
Time-by-matched peer group FE & yes & yes & yes & yes & yes \\
Stock FE & yes & yes & yes & yes & yes \\
Observations & 6,150 & 6,150 & 6,150 & 6,150 & 6,150 \\
R-squared & 0.739 & 0.931 & 0.691 & 0.928 & 0.940 \\
\hline
\end{tabular}


Table 9: S\&P 500 inclusion and stock return sensitivity to market performance

This table examines the effect of S\&P 500 index inclusion on the sensitivity of monthly stock returns to differential asset class performance during 2010-2018. The sample contains S\&P 500 stocks and control stocks matched on industry, size, and liquidity, following Denis et al. (2003). The dependent variable 7-factor alpha is the risk-adjusted return winsorized at $1 \%$ and $99 \%$, where the factors include Market-rf, SMB, HML (Fama and French, 1993), momentum (Carhart, 1997), liquidity (Pástor and Stambaugh, 2003), profitability, and investment (Fama and French, 2015). Beta loadings are estimated using 1996-2005 (36-month rolling windows) in panel A (panel B). $S \& P 500_{m}$ equals one if a stock is included in the S\&P 500 index in month $m$, and zero otherwise. Return $n_{m-1}$ and Return $n_{m-6 \text { to } m-2}$ are raw returns in month $m-1$ and cumulative raw returns during months $m-6$ to $m-2$, respectively. The pre-PPA period (falsification test) includes 1987-2005 and factor betas for that test use the window 1977-1986 in panel A and 36-month rolling windows in panel B. Control variables include log of lagged values of Market capitalization, Monthly volume/Shares out., Market-to-book ratio, and lagged values of Dividend yield 12m, ROE, Investment, Illiquidity, and Mutual fund ownership. Standard errors in this table are clustered two ways by time and stock.

\begin{tabular}{|c|c|c|c|c|c|}
\hline & (1) & (2) & (3) & (4) & (5) \\
\hline A. & \multicolumn{4}{|c|}{$\begin{array}{l}\text { 2010-2018 } \\
\text { 7-Factor alpha pre-window }{ }_{m}\end{array}$} & Pre-PPA \\
\hline$\left(R^{E}-R^{B}\right)_{m} \times S \& P 500_{m}$ & $\begin{array}{l}-0.087 \\
(0.065)\end{array}$ & $\begin{array}{l}-0.084 \\
(0.070)\end{array}$ & $\begin{array}{l}-0.090 \\
(0.073)\end{array}$ & $\begin{array}{l}-0.091 \\
(0.103)\end{array}$ & $\begin{array}{c}0.428 \\
(0.365)\end{array}$ \\
\hline$\left(R^{E}-R^{B}\right)_{m-1} \times S \& P 500_{m}$ & $\begin{array}{c}-0.082^{* * *} \\
(0.030)\end{array}$ & $\begin{array}{c}-0.075^{* *} \\
(0.037)\end{array}$ & $\begin{array}{c}-0.093^{* *} \\
(0.039)\end{array}$ & $\begin{array}{c}-0.153^{* * *} \\
(0.049)\end{array}$ & $\begin{array}{l}0.972^{* *} \\
(0.438)\end{array}$ \\
\hline$S \& P 500_{m}$ & $\begin{array}{c}-0.019^{* * *} \\
(0.005)\end{array}$ & $\begin{array}{l}-0.005 \\
(0.005)\end{array}$ & $\begin{array}{l}-0.006 \\
(0.005)\end{array}$ & $\begin{array}{l}-0.006 \\
(0.006)\end{array}$ & $\begin{array}{c}0.019 \\
(0.096)\end{array}$ \\
\hline Return $_{m-1}$ & & & $\begin{array}{l}-0.062^{* * *} \\
(0.016)\end{array}$ & $\begin{array}{c}-0.061^{* * *} \\
(0.016)\end{array}$ & $\begin{array}{l}-0.127 \\
(0.089)\end{array}$ \\
\hline Return $_{m-6}$ to $m-2$ & & & $\begin{array}{l}-0.012 \\
(0.009)\end{array}$ & $\begin{array}{c}-0.012 \\
(0.009)\end{array}$ & $\begin{array}{l}-0.024 \\
(0.034)\end{array}$ \\
\hline Controls & no & yes & yes & yes & yes \\
\hline Characteristics $\times\left(R^{E}-R^{B}\right)$ & no & no & no & yes & yes \\
\hline Time-by-peer-group FE & yes & yes & yes & yes & yes \\
\hline Stock FE & yes & yes & yes & yes & yes \\
\hline Observations & 19,695 & 16,752 & 16,306 & 16,306 & 711 \\
\hline R-squared & 0.241 & 0.263 & 0.263 & 0.265 & 0.648 \\
\hline$B$. & \multicolumn{5}{|c|}{ 7-Factor alpha rolling-window $w_{m}$} \\
\hline$\left(R^{E}-R^{B}\right)_{m} \times S \& P 500_{m}$ & $\begin{array}{l}-0.020 \\
(0.030)\end{array}$ & $\begin{array}{l}-0.041 \\
(0.031)\end{array}$ & $\begin{array}{c}-0.028 \\
(0.031)\end{array}$ & $\begin{array}{l}-0.019 \\
(0.045)\end{array}$ & $\begin{array}{l}-0.037 \\
(0.090)\end{array}$ \\
\hline$\left(R^{E}-R^{B}\right)_{m-1} \times S \& P 500_{m}$ & $\begin{array}{c}-0.091^{* * *} \\
(0.030)\end{array}$ & $\begin{array}{c}-0.102^{* * *} \\
(0.031)\end{array}$ & $\begin{array}{c}-0.103^{* * *} \\
(0.033)\end{array}$ & $\begin{array}{c}-0.134^{* * *} \\
(0.041)\end{array}$ & $\begin{array}{c}0.070 \\
(0.089)\end{array}$ \\
\hline$S \& P 500_{m}$ & $\begin{array}{c}-0.020^{* * *} \\
(0.004)\end{array}$ & $\begin{array}{l}-0.003 \\
(0.005)\end{array}$ & $\begin{array}{l}-0.005 \\
(0.005)\end{array}$ & $\begin{array}{l}-0.005 \\
(0.006)\end{array}$ & $\begin{array}{c}0.012 \\
(0.010)\end{array}$ \\
\hline Return $_{m-1}$ & & & $\begin{array}{l}-0.046^{* * *} \\
(0.013)\end{array}$ & $\begin{array}{c}-0.046^{* * *} \\
(0.014)\end{array}$ & $\begin{array}{c}-0.087^{* *} \\
(0.036)\end{array}$ \\
\hline Return $_{m-6}$ to $m-2$ & & & $\begin{array}{l}-0.008 \\
(0.007)\end{array}$ & $\begin{array}{l}-0.008 \\
(0.007)\end{array}$ & $\begin{array}{c}-0.036^{* *} \\
(0.014)\end{array}$ \\
\hline Controls & no & yes & yes & yes & yes \\
\hline Characteristics $\times\left(R^{E}-R^{B}\right)$ & no & no & no & yes & yes \\
\hline Time-by-peer-group FE & yes & yes & yes & yes & yes \\
\hline Stock FE & yes & yes & yes & yes & yes \\
\hline Observations & 27,329 & 22,972 & 22,445 & 22,445 & 20,296 \\
\hline R-squared & 0.195 & 0.222 & 0.223 & 0.224 & 0.238 \\
\hline
\end{tabular}


Table 10: Summary statistics on corporate bond funds and corporate bonds

Panel A (B) presents summary statistics of corporate bond funds (corporate bonds) with high and low TDF investment. High (low) TDF indicates if a fund (bond) has above (below) median TDF ownership in cross sections. Zero TDF indicates zero holding by TDFs in a fund (bond). The sample of corporate bond funds includes mutual funds with Lipper classifications of A, BBB, HY, SII, SID, IID, or CRSP objective codes starting in IC. Funds where fraction of corporate bond holdings is less than $20 \%$, or where the growth rate in assets is below $-50 \%$ or above $200 \%$, are excluded (Choi et al., 2020). Frac. held by TDFs for a bond fund is calculated as the total value of TDF holdings of a fund divided by the fund total net assets (TNA). Cash / Fund TNA (\%) represents the values invested in cash, treasuries and money market funds, divided by the fund size. $V W$ rating shows the value-weighted numerical rating (between 1 and 22, with 1 being the highest-rated, equivalent to AAA in S\&P rating) of the underlying corporate bonds. Return is the monthly return measured with end-of-month prices. Rating is the numerical rating (between 1 and 22) of the corporate bond. Frac. held by TDFs for a corporate bond refers to the fraction of the bond indirectly held by TDFs through mutual funds and measured at the end of the previous quarter. Frac. held by mutual funds is the fraction of a bond held by corporate bond mutual funds that have no investment from TDFs. Amount outstanding measures the dollar value of the issue that remains outstanding. Years to maturity is the (integer) number of years until maturity. Years since issuance is the number of years since the issuance date. Monthly volume/amount out stands for the monthly total dollar trading volume divided by the amount outstanding. Roll illiquidity is the monthly average Roll (1984) measure of effective bid-ask spread based on first-order serial covariance of price changes. ZTD standards for the fraction of zero-trading days and is the percentage of days during a quarter on which a bond is not traded. Return $n_{m}$ is the lagged raw monthly return. Return $n_{m-6}$ to $m-2$ is the cumulative return from month $m-6$ to $m-2$. p-values of difference tests on means between high TDF and low TDF are reported.

\begin{tabular}{|c|c|c|c|c|c|c|c|}
\hline \multirow[b]{2}{*}{ A. Corporate bond funds quarterly } & \multicolumn{2}{|c|}{$\begin{array}{c}\text { High TDF } \\
N=1,038\end{array}$} & \multicolumn{2}{|c|}{$\begin{array}{l}\text { Low TDF } \\
N=1,057\end{array}$} & \multicolumn{2}{|c|}{$\begin{array}{c}\text { Zero TDF } \\
\mathrm{N}=14,332\end{array}$} & \multirow{2}{*}{$\begin{array}{c}\text { p-value } \\
\text { High=Low }\end{array}$} \\
\hline & Mean & SD & Mean & SD & Mean & $\mathrm{SD}$ & \\
\hline Frac. held by TDFs (\%) & 19.51 & 23.72 & 0.55 & 0.70 & 0.00 & 0.00 & 0.00 \\
\hline Cash / Fund TNA (\%) & 16.96 & 17.01 & 11.76 & 15.79 & 11.25 & 14.21 & 0.00 \\
\hline Corporate bonds / Fund TNA (\%) & 34.32 & 12.66 & 45.22 & 18.97 & 45.47 & 19.96 & 0.00 \\
\hline \multirow[t]{2}{*}{$V W$ rating } & 9.43 & 2.67 & 10.39 & 3.05 & 9.93 & 2.99 & 0.00 \\
\hline & \multicolumn{2}{|c|}{$\begin{array}{c}\text { High TDF } \\
\mathrm{N}=205,908\end{array}$} & \multicolumn{2}{|c|}{$\begin{array}{c}\text { Low TDF } \\
\mathrm{N}=194,947\end{array}$} & \multicolumn{2}{|c|}{$\begin{array}{l}\text { Zero TDF } \\
\mathrm{N}=58,991\end{array}$} & $p$-value \\
\hline B. Corporate bonds monthly & Mean & SD & Mean & SD & Mean & SD & High $=$ Low \\
\hline Return $_{m}(\%)$ & 0.294 & 1.906 & 0.381 & 2.092 & 0.623 & 2.256 & 0.00 \\
\hline Rating $m$ & 8.148 & 2.862 & 9.127 & 3.672 & 9.638 & 4.079 & 0.00 \\
\hline Frac. held by TDFs $s_{q-1}(\%)$ & 0.692 & 0.993 & 0.092 & 0.098 & 0.000 & 0.000 & 0.00 \\
\hline Frac. held by mutual funds ${ }_{q-1}(\%)$ & 6.797 & 6.197 & 6.879 & 6.889 & 6.972 & 7.889 & 0.00 \\
\hline Amount outstanding ${ }_{m-1}$ (\$ million) & 914.3 & 752.5 & 702.9 & 504.5 & 569.5 & 572.4 & 0.00 \\
\hline Years to maturitym & 9.488 & 9.298 & 8.615 & 8.745 & 8.333 & 9.316 & 0.00 \\
\hline Years since issuance $_{m}$ & 3.192 & 3.004 & 4.010 & 3.764 & 5.082 & 4.745 & 0.00 \\
\hline Monthly volume / amount out $t_{m-1}$ & 0.057 & 0.060 & 0.058 & 0.065 & 0.068 & 0.076 & 0.00 \\
\hline Roll illiquidity $q-1$ & 0.007 & 0.007 & 0.009 & 0.010 & 0.013 & 0.014 & 0.00 \\
\hline$Z T D_{q-1}$ & 0.455 & 0.257 & 0.505 & 0.249 & 0.571 & 0.242 & 0.00 \\
\hline Return $_{m-1}(\%)$ & 0.301 & 1.910 & 0.376 & 2.095 & 0.749 & 2.287 & 0.00 \\
\hline Return $_{m-6 \text { to } m-2}(\%)$ & 1.785 & 4.361 & 1.944 & 5.041 & 3.735 & 5.225 & 0.00 \\
\hline Return $_{m-12 \text { to } m-2(\%)}$ & 0.043 & 0.062 & 0.045 & 0.074 & 0.076 & 0.079 & 0.00 \\
\hline
\end{tabular}




\section{Table 11: TDFs and aggregate return autocorrelation}

This table reports the autocorrelation in monthly returns of the U.S. equity market as a function of the fraction of the equity market held by TDFs or TDBFs (including TDFs, target-date collective investment trusts, and balanced funds). The dependent variable is the raw monthly return of the U.S. stock market $\left(R^{E}\right)$ in columns 1-2 and the excess return of equity over bonds $\left(R^{E}-R^{B}\right)$ in columns 3-4. TDF (TDBF) fraction is estimated fraction of the U.S. equity market held by TD(B)Fs and is estimated at the end of the previous year, assuming $40 \%$ of the total assets of the TD(B)Fs are invested in the U.S. stock market (assuming $60 \%$ equity allocation at the $\mathrm{TD}(\mathrm{B}) \mathrm{F}$ and 2:1 domestic to foreign equity ratio). Total value of the U.S. stock market is obtained from CRSP. Standard errors are estimated using the Newey-West method, with one lag in the error structure.

\begin{tabular}{|c|c|c|c|c|}
\hline & (1) & (2) & (3) & (4) \\
\hline & \multicolumn{4}{|c|}{ Return $_{m}$} \\
\hline & \multicolumn{2}{|c|}{$R^{E}$} & \multicolumn{2}{|c|}{$R^{E}-R^{B}$} \\
\hline Return $_{m-1}$ & $\begin{array}{l}0.293^{* *} \\
(0.129)\end{array}$ & $\begin{array}{l}0.329^{* *} \\
(0.151)\end{array}$ & $\begin{array}{l}0.252^{* *} \\
(0.121)\end{array}$ & $\begin{array}{l}0.284^{* *} \\
(0.140)\end{array}$ \\
\hline Return $_{m-1} \times$ TDF fraction f $_{y-1}$ & $\begin{array}{c}-37.198^{* *} \\
(14.500)\end{array}$ & & $\begin{array}{c}-33.449 * * \\
(13.447)\end{array}$ & \\
\hline Return $_{m-1} \times$ TDBF fraction $_{y-1}$ & & $\begin{array}{c}-9.745^{* *} \\
(4.479)\end{array}$ & & $\begin{array}{c}-8.861^{* *} \\
(4.193)\end{array}$ \\
\hline TDF fraction f $_{y-1}$ & $\begin{array}{l}1.080^{* *} \\
(0.541)\end{array}$ & & $\begin{array}{l}1.195^{* *} \\
(0.569)\end{array}$ & \\
\hline TDBF fraction f $_{y-1}$ & & $\begin{array}{l}0.347^{* *} \\
(0.173)\end{array}$ & & $\begin{array}{l}0.385^{* *} \\
(0.183)\end{array}$ \\
\hline Constant & $\begin{array}{c}-0.001 \\
(0.005)\end{array}$ & $\begin{array}{l}-0.004 \\
(0.006)\end{array}$ & $\begin{array}{c}-0.004 \\
(0.005)\end{array}$ & $\begin{array}{l}-0.007 \\
(0.006)\end{array}$ \\
\hline Observations & 228 & 228 & 228 & 228 \\
\hline F & 2.721 & 2.301 & 2.547 & 2.439 \\
\hline DF residual & 224 & 224 & 224 & 224 \\
\hline DF model & 3 & 3 & 3 & 3 \\
\hline
\end{tabular}

